OPEN ACCESS

Edited by:

Gabriella Martino,

Università degli Studi di Messina, Italy

Reviewed by:

Hatta Sidi,

National University of

Malaysia, Malaysia

Maria Cristina Gugliandolo,

University of Cassino, Italy

*Correspondence:

Amanda C. LaRue

laruerc@musc.edu

${ }^{t}$ These authors have contributed equally to this work and share first authorship

Specialty section: This article was submitted to

Psychopathology,

a section of the journal

Frontiers in Psychiatry

Received: 03 January 2019 Accepted: 20 March 2019

Published: 09 April 2019

Citation:

Kelly RR, McDonald $L T$, Jensen NR,

Sidles SJ and LaRue AC (2019) Impacts of Psychological Stress on

Osteoporosis: Clinical Implications and Treatment Interactions.

Front. Psychiatry 10:200

doi: 10.3389/fpsyt.2019.00200

\section{Impacts of Psychological Stress on Osteoporosis: Clinical Implications and Treatment Interactions}

\author{
Ryan R. Kelly ${ }^{1,2 \dagger}$, Lindsay T. McDonald ${ }^{1,2 \dagger}$, Nathaniel R. Jensen ${ }^{1,2}$, Sara J. Sidles ${ }^{1,2}$ and \\ Amanda C. LaRue ${ }^{1,2 *}$
}

${ }^{1}$ Research Services, Ralph H. Johnson VA Medical Center, Charleston, SC, United States, ${ }^{2}$ Department of Pathology and Laboratory Medicine, Medical University of South Carolina, Charleston, SC, United States

The significant biochemical and physiological effects of psychological stress are beginning to be recognized as exacerbating common diseases, including osteoporosis. This review discusses the current evidence for psychological stress-associated mental health disorders as risk factors for osteoporosis, the mechanisms that may link these conditions, and potential implications for treatment. Traditional, alternative, and adjunctive therapies are discussed. This review is not intended to provide therapeutic recommendations, but, rather, the goal of this review is to delineate potential interactions of psychological stress and osteoporosis and to highlight potential multi-system implications of pharmacological interventions. Review of the current literature identifies several potentially overlapping mechanistic pathways that may be of interest (e.g., glucocorticoid signaling, insulin-like growth factor signaling, serotonin signaling) for further basic and clinical research. Current literature also supports the potential for cross-effects of therapeutics for osteoporosis and mental health disorders. While studies examining a direct link between osteoporosis and chronic psychological stress are limited, the studies reviewed herein suggest that a multi-factorial, personalized approach should be considered for improved patient outcomes in populations experiencing psychological stress, particularly those at high-risk for development of osteoporosis.

Keywords: osteoporosis, bone, psychological stress, mental health, depression, PTSD, pharmacology, alternatives

\section{BACKGROUND}

Emerging evidence points to the potential pathological impact of mental health on disease. It has long been held that stress has negative impacts on health and disease risk, but the specific mechanisms by which this occurs, as well as implications for treatments and clinical recommendations, have not been examined in-depth. This review will provide an overview of recent literature regarding the impact of psychological stress and stress-related disorders, such as post-traumatic stress disorder (PTSD), depression, and anxiety, on risk and treatment of osteoporosis. In this review, we first highlight mechanisms that impact both bone health and mental health toward identification of potentially overlapping signaling pathways. We then review current literature regarding the impact of common therapeutic agents for treatment of osteoporosis and mental health disorders. This will promote recognition of the potential interaction of these therapeutic agents in patients with concurrent mental health disorders and osteoporosis to encourage a broad view of disease management toward improved patient health. 
Finally, we provide a perspective outlook on the potentially beneficial effects of alternative treatments, such as exercise and nutritional supplementation, on both osteoporosis and psychological stress.

\section{OSTEOPOROSIS}

There are four major bone cell types: osteoclasts, osteoblasts, osteocytes, and osteogenic stem cells. Osteoclasts, which are of myeloid origin, are giant, multinucleated cells that adhere to the bone and resorb it through acidification and proteolytic digestion. Osteoblasts counteract osteoclast-mediated bone resorption by secreting osteoid, which mineralizes to form new bone. There is a tightly-regulated balance between osteoclastmediated removal of old or damaged bone and osteoblastmediated replacement of new bone to maintain bone mass and skeletal homeostasis. After secretion of osteoid, osteoblasts either become trapped within the osteoid and terminally differentiate into osteocytes, quiesce into bone lining cells, or undergo apoptosis. Osteocytes comprise $90-95 \%$ of the bone cell population (1). Once they become embedded in the mineralized tissue, they develop cytoplasmic projections that intercalate throughout the bone, creating a signaling network to communicate directly with other osteocytes (2). Through this network, osteocytes regulate phosphate homeostasis and transduce mechanical stress signals into biologic activity to stimulate either bone resorption or formation. Osteogenic stem cells are the source of osteoblasts and osteocytes and are involved in bone repair, regeneration, and development. The functions and number of these cell types can become disrupted following bone damage or in disease states, such as osteoporosis.

Osteoporosis is the most common form of metabolic bone disease and is characterized by low bone mass and microarchitectural bone deterioration. The World Health Organization defines osteoporosis as a bone mineral density (BMD) that is $\leq 2.5$ standard deviations below peak bone mass, which is typically achieved around age 30. In the United States alone, osteoporosis accounts for over 1.5 million fractures per year (3). By 2025, treatment costs are estimated to exceed $\$ 25$ billion (4). Osteoporosis is characterized by an imbalance of skeletal remodeling, resulting in increased osteoclast activity and/or decreased numbers of osteoblasts, which can lead to decreased

\footnotetext{
Abbreviations: ALP, Alkaline Phosphatase; ASD, Acute Stress Disorder; BDNF, Brain-Derived Neurotrophic Factor; BMD, Bone Mineral Density; BMPs, Bone Morphogenic Proteins; CNS, Central Nervous System; COLI, Procollagen Type I; DHA, Docosahexaenoic Acid; EPA, Eicosapantaenoic Acid; FDA, Food and Drug Administration; GABA, Gamma-Aminobutyric Acid; GAD, Generalized Anxiety Disorder; $\mathrm{H}_{2} \mathrm{O}_{2}$, Hydrogen Peroxide; HPA, Hypothalamic-Pituitary Adrenal; IGF1, Insulin Growth Factor-1; IGFBPs, Insulin Growth Factor Binding Proteins; mTOR, Mammalian Target of Rapamycin; MDD, Major Depressive Disorder; MSCs, Mesenchymal Stromal Cells; NFкB, Nuclear Factor Kappa B; NMDAR, $\mathrm{N}$-methy-D-aspartate receptor; OCN, Osteocalcin; OPG, Osteoprotegerin; PTH, Parathyroid Hormone; PTHR1, Parathyroid Hormone Receptor-1; PTSD, PostTraumatic Stress Disorder; QOL, Quality of Life; RANKL, Nuclear Factor Kappa B Receptor Ligand; ROS, Reactive Oxygen Species; SAM, Sympathomedullary; SERMs, Selective Estrogen Receptor Modulators; SSRI, Selective-Serotonin Reuptake Inhibitors; TGF $\beta$, Transforming Growth Factor- $\beta$; TNF- $\alpha$, Tumor Necrosis Factor- $\alpha$.
}

bone strength and mass, as well as increased susceptibility to fracture.

Osteoporosis is an umbrella term for a group of distinct pathological conditions and has been traditionally classified into primary and secondary types based on mechanism of disease (5). There are two main types of primary osteoporosis: type I osteoporosis and type II osteoporosis. Type I osteoporosis occurs most frequently in postmenopausal women and primarily results from estrogen deficiency. Estrogens inhibit production of receptor activator of nuclear factor kappa-B ligand (RANKL), which is crucial for osteoclast differentiation and recruitment, as well as interleukin (IL)-1, IL-6, and tumor necrosis factoralpha $(\mathrm{TNF}-\alpha)(6,7)$. In addition, estrogens promote osteoblast differentiation and positively regulate several anabolic bonerelated proteins, including insulin-like growth factor-1 (IGF-1), bone morphogenetic proteins (BMPs), and procollagen type I (COL1) (8). Thus, postmenopausal decrease in estrogen may affect both bone resorption and bone formation. The functional outcome is a rate of bone resorption that is higher than that of bone formation, resulting in a net decrease in bone mass. Type II osteoporosis is associated with aging and is commonly observed in men and women after the age of 60 . Aging results in a progressive decline in osteoblast numbers and decreased osteoblast activity, but no change in osteoclast activity. It is still unknown how the cellular and molecular mechanisms that contribute to these two primary types of osteoporosis compare to each other or to what extent sex steroid deficiency contributes to age-related skeletal degradation. Findings in mouse models suggest that the effects of age on skeletal health are independent of estrogens, but data describing a similar mechanism in humans is lacking $(9,10)$.

Secondary osteoporosis is characterized by bone loss resulting from an underlying etiology, such as Cushing's syndrome, or prolonged treatment with glucocorticoids. In glucocorticoidinduced osteoporosis, bone loss occurs within several months of glucocorticoid treatment and can lead to significant decreases in cancellous bone mass and increased fracture risk. Excess glucocorticoids exert an inhibitory effect on osteoblast differentiation (11). Glucocorticoid-induced osteoporosis is the most common form of secondary osteoporosis and is the most common form of osteoporosis among young people [reviewed in Briot and Roux (12)]. Secondary osteoporosis can also be caused by disuse. Prolonged bone unloading, as seen in extended bed rest or space travel, inhibits bone formation and enhances bone resorption. This occurs due to the lack of appropriate regulation of bone mass by the osteocyte network and, possibly, through involvement of the sympathetic nervous system (13).

Although decreased BMD is what defines osteoporosis, this factor alone is not a major cause of pain or morbidity. Instead, morbidity associated with osteoporosis is primarily due to increased incidence of fragility fracture. Due to the biomechanical and biological alterations in osteoporotic bones, only a minor external force, such as a short fall, is required to induce a fracture. Osteoporotic fractures are three times more likely in women and typically occur after the age of 50 (14). Not only does osteoporosis increase fracture 
risk, but it is also associated with poorer fracture healing outcomes [reviewed in Cheung et al. (15)]. Current treatment strategies are aimed at increasing calcium and vitamin D levels through supplementation, inhibiting bone resorption through bisphosphonate administration, and mitigating the effects of menopause through hormone replacement (discussed in detail below). The FDA has also approved the anabolic agent, human parathyroid hormone (PTH) peptide, to treat osteoporosis. In addition, newer therapies, such as strontium ranelate administration and antibodies against RANKL, are being investigated (16). Stem cell therapies are being examined for their ability to enhance repair of fractures (17). Transplantation of allogeneic non-osteoporotic stem cells may be able to normalize the aberrant bone remodeling that occurs in osteoporotic patients, thereby reducing fracture risk (18). However, the optimal stem cell phenotype and method of delivery are still poorly characterized (19). There is an ongoing need to identify, develop, and improve therapeutics that reduce fracture risk, enhance bone mineral density, and promote fracture healing.

\section{PSYCHOLOGICAL STRESS}

Psychological stress is defined as an emotional experience that is accompanied by predictable biochemical, physiological, and behavioral changes (20). Psychological stress can occur in response to an acute event, as in a fight-or-flight response to a life-threatening or traumatic event, or stress can be chronic, as in the case of caregivers, service members, and high-stress occupations. In acute psychological and physical stress, stress signaling is initiated through the hypothalamic-pituitary-adrenal (HPA) axis and the sympathomedullary (SAM) pathway via secretion of stress hormones, which include glucocorticoids (cortisol) and catecholamines (epinephrine, norepinephrine). Immune cells (leukocytes) express receptors for these hormones (glucocorticoid receptors and adrenergic receptors, respectively) and rapidly respond to their induction by altering the inflammatory immune response. However, in chronic stress and chronic stress-associated mental health conditions, the HPA-axis becomes dysregulated, resulting in hypercortisolism or glucocorticoid resistance (21). Whether the stress response becomes pathologic is dependent on many factors, including individual coping skills, life history, severity, and duration of the stressor.

Anxiety or depression disorders can arise as a result of acute or chronic stress. Depressive mood disorders, such as major depressive disorder (MDD), are characterized by persistent emotional and physical symptoms, including depressed mood, loss of interest and enjoyment (anhedonia), and dysregulated sleep. Depression is often comorbid with anxiety, and both conditions can alter the HPA response. Anxiety can manifest as excessive worry, fear, irritability, difficulty concentrating, and with physical symptoms, such as increased heart rate and breathlessness. Mental health disorders, such as depression, result in a variety of potentially detrimental biochemical and physiological changes [reviewed in Yang et al. (22)]. Other stress-related conditions include acute stress disorder (ASD), in which individuals experience a constellation of symptoms, such as anxiety, flashbacks, and distress related to and surrounding a traumatic event. When these symptoms persist beyond the acute phase of 1 month, they are recognized as the chronic condition, termed post-traumatic stress disorder (PTSD). PTSD is recognized as an extreme case of chronic stress in which symptoms can persist for months to years. It is defined by display of symptoms that include heightened response to events or circumstances related to an initial traumatic and/or lifethreatening event. Symptoms of PTSD are both intrusive, such as flashbacks and unwanted upsetting memories, and avoidant, such as evasion of stimuli that could recall the initiating trauma. Together, these symptoms have a significant impact on patient quality of life (QOL) and can lead to severe anxious, depressive, and debilitating effects (23). PTSD impacts approximately $3.6 \%$ of individuals annually, with increased incidence among Veteran populations, for whom rates have approached $20 \%$ in those returning from recent conflicts in Afghanistan and Iraq (24, 25). Estimates of the number of individuals with mental health disorders, or even those experiencing short-term psychological stress, are difficult to obtain, partially owing to the fear of stigmatism and rejection that may accompany mental health disorder diagnosis. Nonetheless, mental health disorders impact a significant percentage of the population, and it is becoming increasingly clear that psychological stress has significant impact on patient QOL, as well as physical health.

\section{PSYCHOLOGICAL STRESS AS A RISK FACTOR FOR OSTEOPOROSIS}

Psychological stress can have lasting impact on risk for development of comorbid disease, as well as significant impact on pre-existing diseases. Chronic stress has been associated with obesity, atherosclerosis, lung pathologies, and diabetes $(26,27)$. In regard to osteoporosis, U.S. military veterans diagnosed with PTSD have a higher risk of developing osteoporosis (28), as do civilians with PTSD diagnosis (29). Likewise, it was found that among 73 female Holocaust survivors there was a 3.47fold increase in prevalence of osteoporosis compared to controls (30), suggesting psychological stress may be a risk factor for osteoporotic disease. However, malnutrition and other factors likely played a role as well, although the authors did not discuss this possibility. A recent mouse study by Foertsch et al. showed that chronic stress induced by a chronic subordinate colony housing model of PTSD resulted in reduced growth plate endochondral ossification in adolescent mice (31). Increased expression of tyrosine hydroxylase (a catalytic enzyme involved in catecholamine biosynthesis) by bone marrow cells located in the growth plates of the femurs of chronically stressed mice suggested that decreased bone length and density may be due to stress-induced catecholamine impact on bone growth.

While the mechanisms underlying the physiological and biochemical impact of psychological stress on disease are not well-understood, several studies have shown that stress hormone signaling via the brain-immune connection is a significant contributor (32). Chronic stress has been associated 


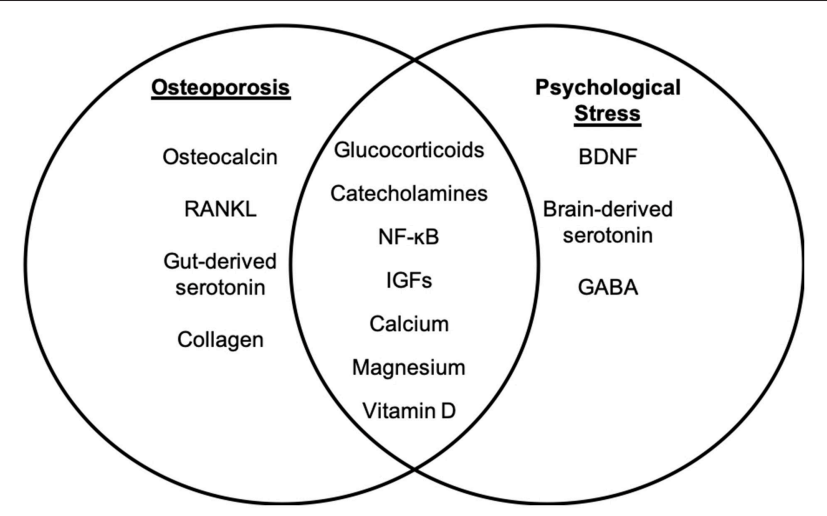

FIGURE 1 | Molecular targets of osteoporosis and psychological stress. While psychological stress and osteoporosis occur via distinct mechanisms, there are several factors that overlap between psychological stress-associated mental health disorders and osteoporosis. The molecular factors that are distinct to osteoporosis (left panel) and psychological stress (right panel) are listed. Intersecting factors related to osteoporosis and psychological stress are listed in the (middle panel).

with increased systemic inflammation $(26,27,33)$ and altered hematopoiesis (34). Inflammatory factors have been shown to have a detrimental effect on osteoporosis through promotion of osteoclast differentiation and apoptosis of osteoblast populations [reviewed in Eastell et al. (35)]. It has also been suggested that a number of inflammatory factors may actually exhibit inhibitory effects on osteoclast activity, thereby potentially improving bone health in osteoporosis (36). Thus, while common to both conditions, the roles of inflammatory factors in osteoporosis and in psychological stress are likely highly complex and both context- and dose-dependent. A review of the current literature identifies several additional pathways and cellular mechanisms that are common to chronic psychological stress and osteoporosis. Literature is limited in terms of studies examining any direct mechanistic interaction between these pathways in the context of osteoporosis and psychological stress; however, independent examination of the mechanisms of disease and shared risk factors suggests that further research is warranted. The studies below, and summarized in Figures 1 and 2, discuss several of these common pathways, cellular and molecular mechanisms, and risk factors to highlight the potential for future examination of the role of chronic psychological stress/mental health on osteoporosis.

\section{Glucocorticoids}

In chronic psychological stress, dysregulated glucocorticoid signaling has profound impacts on inflammation and may also contribute to disease risk (21). Stress-induced dysregulation of endogenous glucocorticoids may mimic the skeletal effects of glucocorticoid-induced osteoporosis. Glucocorticoids are hormones that exert their effects largely by entering the nucleus and modulating gene transcription. Glucocorticoidresponsive transcription factors are primary regulators of inflammation resulting from stress hormone signaling and include NF- $\mathrm{B}$. There is some evidence to suggest that

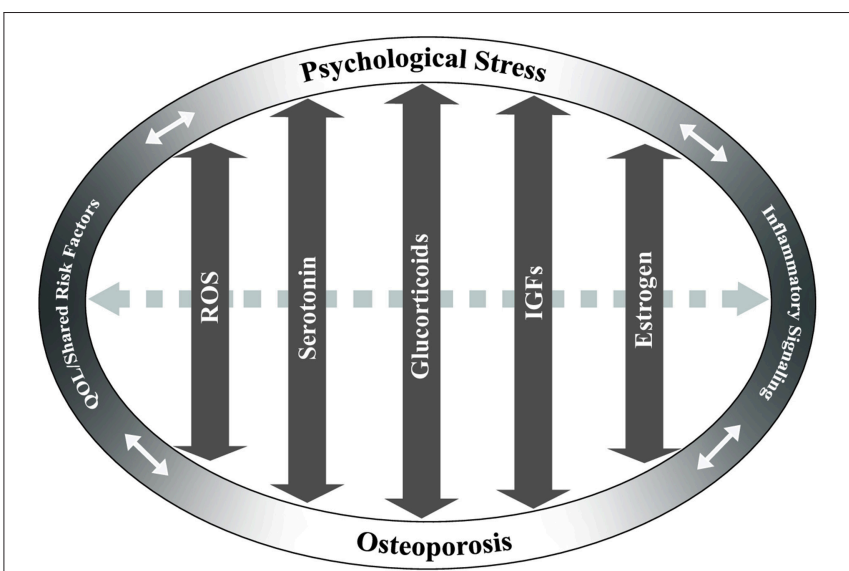

FIGURE 2 | Potentially overlapping pathways of osteoporosis and psychological stress. Key pathways that may have overlapping effects between chronic stress and osteoporosis are identified based on current literature. These include reactive oxygen species (ROS), serotonin, glucocorticoid, insulin-like growth factor (IGF), and estrogen signaling pathways. Arrows indicate the potential of these pathways/factors to influence both chronic stress and osteoporosis in a bi-directional fashion. Dashed gray arrow between pathways indicates potential interactions between the pathways. Quality of life (QOL)/shared risk factors and inflammatory signaling are positioned at ends of ellipse to demonstrate cross-effects between chronic psychological stress and/or osteoporosis.

activation of NF- $\mathrm{B}$ through glucocorticoid responsive elements in response to psychological stress may contribute to the risk of osteoporosis through RANK signaling (37). In addition, glucocorticoids are known to act directly on bone cells, leading to decreased osteocyte viability, decreased osteoblast function due to reductions in IGF-2, and prolonged osteoclast viability [reviewed in Briot and Roux (12)]. Therefore, psychological stress may negatively impact bone health through modulation of endogenous glucocorticoids.

\section{Catecholamines}

Catecholamines are stress hormones that include norepinephrine, epinephrine, and dopamine. Norepinephrine and epinephrine are released by the adrenal glands as part of the rapid fight-or-flight response to stress. This elevation is typically in response to a physical stressor; however, psychological stress (e.g., sudden bad news, fear, or PTSD-related flashbacks) can also trigger catecholamine release. Chronic and/or repeated elevations in norepinephrine or epinephrine in response to psychological stress may contribute to the development of depression (38). Dopamine is also increased in specific brain regions in response to pain or stress. Like other catecholamines, dopamine may become dysregulated in the case of chronic stress [reviewed in Vaessen et al. (39)].

One way in which psychological stress may impact osteoporotic disease risk and severity is through catecholamineinduced activation of $\beta$-adrenergic receptors on osteoblasts and osteoclasts. $\beta$-adrenergic receptor activation has been shown to increase RANKL expression, resulting in osteoclast differentiation (40). Treatment with a $\beta$-agonist resulted in 
bone loss due to increased bone resorption (41). $\beta$-adrenergic signaling was also shown to exacerbate bone loss through promotion of osteoclastogenesis via generation of reactive oxygen species (ROS) (42). These studies suggest that alterations in catecholamines due to chronic stress may impact bone health and contribute to risk and severity of osteoporosis.

\section{Myeloid Populations}

Chronic psychological stress has been shown to alter myeloid phenotype and increase myelopoeisis. Activation and increased contribution of myeloid populations are significant in that myeloid-derived immune cells are the primary mediators of the inflammatory response promoted by chronic stress (43). The myeloid response to chronic stress may significantly contribute to bone health and osteoporotic disease, given that osteoclasts are myeloid-derived, and monocytes are well-known for their plasticity during wound repair. However, the role of myeloid cells in bone health is complex. Depletion of macrophages in mice was shown to lead to early skeletal growth retardation and osteoporosis and decreased the number of bone marrowderived mesenchymal stromal cells (MSCs) present in the bones (44). Further, these so-called "osteomacs" were shown to be closely associated with areas of bone remodeling and were directly involved in formation of the canopy structure that makes up the bone-remodeling compartment. Depletion of osteomacs caused complete loss of this compartment. However, removal of osteomacs from calvarial cultures decreased markers of osteoblastic function, including osteocalcin (OCN) mRNA expression and mineralization in vitro. Thus, targeting the myeloid cell population as an osteoporotic treatment may not be an optimal approach due to the duality of its effects.

\section{Insulin-Like Growth Factors (IGFs)}

Glucocorticoids and IGFs are known to regulate one another, suggesting that mood may influence levels of IGF-1 $(45,46)$. IGFs may also play a role in psychological stress (47) and osteoporosis (48). Circulating IGF-1 is increased in individuals with depression or anxiety disorders $(49,50)$ and has been shown to be a biomarker for vulnerability of an individual to stress following traumatic brain injury (51). Yu et al. found that, in a single prolonged stress model, IGF-1 levels were up-regulated by approximately $25 \%$ in the stressed group, although this data was not statistically significant (52). Another study by Hoshaw et al. demonstrated an anti-depressant and anti-anxiolytic effect of IGF due to its effects on serotonin (53). These conflicting reports suggests that further research is needed to determine whether IGF has beneficial or detrimental impacts on psychological stressrelated mental health disorders.

In bone health, IGF-1 and-2 regulate osteoblast-osteoclast interactions, thus making them important regulators of bone remodeling (54). IGF-1 has also been shown to activate mammalian target of rapamycin (mTOR) remodeling to stimulate MSC differentiation into osteoblasts (55). Knockout of IGF-1 impairs osteoblast differentiation and leads to decreased trabecular bone formation (56). Its role in fracture healing is still not fully understood, as some studies suggest beneficial effects of IGF-1 treatment, while other studies demonstrate nonsignificant effects (57-59). IGF-1 action and circulating levels also decline with age, and this mechanism has been suggested to be an underlying cause of age-related osteoporosis [reviewed in Perrini et al. (60)]. IGF-2 is most commonly thought of as a fetal growth factor; however, it is the most abundant growth factor stored in adult bone. Induction of the osteogenic lineage from parthenogenetic embryonic stem cells is enhanced with IGF-2 treatment (61). Interestingly, different effects of IGF-1 vs. IGF-2 have been reported in human bone cell metabolic pathways, suggesting they activate different signaling cascades, even though they both primarily signal through the IGF1R $(62,63)$. The differing effects of IGF-1 and IGF-2 could be due to cell-specific expression patterns. It is also possible that the presence and concentration of specific insulin-like growth factor binding proteins (IGFBPs), which mediate IGF bioavailability and are temporally and spatially regulated, may regulate these differing effects. Together, these studies suggest IGF as a potential connecting pathway between osteoporosis and psychological stress. Additional studies are needed to delineate the role of IGF1 vs. IGF-2 and to determine how IGFBPs (64) may be temporally and differentially regulated during osteoporosis, psychological stress, and in osteoporotic patients who have a history of mental health disorders.

\section{Oxidative Stress}

Studies on depressive disorders have shown a significant decrease in neuronal and glial cells in depressed patients. It has been suggested that the decline in these populations is due to an increased amount of ROS [reviewed in Michel et al. (65)]. ROS have been shown to induce osteoblast apoptosis, leading to decreased bone formation $(66,67)$. ROS, as well as hydrogen peroxide $\left(\mathrm{H}_{2} \mathrm{O}_{2}\right)$, are required for RANKLinduced osteoclast generation (68-70). Further, increased ROS in the bone marrow compartment can lead to expansion of lymphocytes, altered cytokine production $(71,72)$, and promotion of osteoclastogenesis (42). In regard to impacts on osteoporosis, ovariectomized rats were found to have increased oxidative stress compared to controls. However, treatment with palm tocotrienol, a potent antioxidant, for 8 weeks resulted in suppression of malondialdehyde levels, a marker of oxidative stress, and promotion of plasma glutathione peroxidase and erythrocyte superoxide dismutase activity, two key antioxidant enzymes (73). Thus, palm tocotrienols may have bone protective effects by limiting oxidative stress damage [reviewed in Chin and Ima-Nirwana (74)].

\section{Serotonin}

Serotonin, or 5-hydroxytryptamine (5-HT), is a monoamine neurotransmitter that is involved in a host of important processes, including sleeping, eating, digesting, and mood regulation [reviewed in Sangkuhl et al. (75)]. Serotonin is synthesized both in the gut and in the brain by different isoforms of tryptophan hydroxylase (TPH), TPH-1 and TPH-2, respectively. The vast majority (95\%) of serotonin is produced in the periphery, mainly by enterochromaffin cells in the duodenum. Until recently, it has been thought that serotonin 
does not interact with bone; however, recent studies have begun to unmask a complex role for serotonin in regulating bone mass and bone metabolism [reviewed in Wadhwa et al. (76)]. Serotonin has been shown to regulate osteoblast proliferation and function in vitro (77), and osteoblasts and osteoclasts express a variety of serotonin receptors (Htrla, Htr1b, Htr1d, Htr2a, Htr2b) $(78,79)$. Addition of serotonin to RAW264.7 cells induced osteoclast differentiation through intracellular accumulation of serotonin via the serotonin transporter (SERT or 5-HTT), resulting in upregulation of NF- $\mathrm{B}$ (80). When produced peripherally, serotonin inhibits bone formation and decreases osteoblast proliferation [reviewed in Ducy and Karsenty (81)]. When produced in the brain, serotonin acts as a neurotransmitter to exert a positive effect on bone mass accrual by enhancing bone formation and limiting bone resorption via regulation of the sympathetic response [reviewed in Dimitri and Rosen (82)].

\section{Shared Risk Factors}

Several independent lifestyle risk factors for development of osteoporosis may also be impacted by concurrent stressassociated mental health disorders, such as smoking, alcohol use, and substance abuse. Smoking, in particular, represents a strong risk factor for development of osteoporosis. The direct mechanism(s) by which this occurs are not well understood. However, a study by Ko et al. demonstrated that serum from animals exposed to smoking resulted in increased osteoclast differentiation from macrophages in response to RANKL, as well as a reduction in alkaline phosphatase (ALP) and consequent reduction in osteoblast differentiation (83). In patients seeking mental health care, $28.2 \%$ report smoking, as compared to $17.5 \%$ among the general population (84). This finding suggests that psychological stress is associated with an increased risk for smoking. Due to the reported negative impact of smoking on bone health (85), psychological stress may also indirectly increase risk of osteoporosis. Similarly, alcohol consumption is a significant risk factor for development of osteoporosis (86, 87 ), due, in part, to senescence and ROS production in bone marrow-derived MSCs, which results in decreased osteogenic potential (88). Substance abuse, such as opioid addiction, is also elevated among those suffering with psychological stressassociated mental health disorders ( 18.7 vs. $5 \%$ among those without mental health disorders) (89). Increased rates of osteopenia and osteoporosis have been found among women addicted to opioids (90).

Obesity may represent another risk factor for osteoporosis, due to increased inactivity, leading to cases of unloading. Likewise, as described below, exercise may provide benefit for $\mathrm{BMD}$ and in reducing fracture risk. In addition, obesity leads to increased systemic inflammation, with many of the signals, such as NF- $\mathrm{B}$ and $\mathrm{TNF}-\alpha$, being differentiation factors for osteoclasts as well. There is also a clear link between obesity and development of type 2 diabetes, which is another known risk fracture for development of osteoporotic fracture [reviewed in Walsh and Vilaca (91)]. However, weight gain, itself, may have positive effects on osteoporosis. Weight loss in postmenopausal women was shown to increase risk of frailty fractures (92).
Conversely, weight gain reduced risk of hip fractures, although it does increase risk of other types of fracture $(93,94)$. Clearly, the effects of weight on fracture are complex and require further study.

Together, these studies indicate that, in patients with extreme and/or chronic psychological stress, osteoporotic risk may be exacerbated by compounded effects of these common risk factors. As such, in addition to independent risk factors for osteoporosis, the potential for a multifactorial feedback loop with psychological stress exists and should not be overlooked.

\section{INTERACTION OF TREATMENTS}

Based on the studies above demonstrating potentially overlapping factors, cellular mechanisms, and signaling pathways between osteoporosis and chronic psychological stress, it is not surprising that treatments for these conditions may also have overlapping and opposing effects. Thus, it is critical that the interplay between stress and disease-mediated pathways is considered during the planning of best course of treatment for an osteoporotic patient, particularly one with a history of mental health disorder. While this review does not provide, and is not intended to provide, clinical recommendations, a discussion of current literature and potential crosstalk between treatments for osteoporosis and psychological stressrelated mental health disorders is provided to encourage consideration of the implications of drug selection from a broad, whole-health perspective.

\section{Osteoporosis Treatments}

Given the potential impact of psychological stress and its treatments on bone health, treatments that benefit both bone and mental health may be preferred, especially in patients at high-risk for concurrent osteoporosis and mental health disorders. In this section, we discuss common treatment options for osteoporosis, independent of type, and detail literature that provides evidence of potential impacts of these treatments on mental health. Literature findings outlined below are summarized in Table $\mathbf{1 .}$ For each osteoporotic treatment, we first discuss its primary use and impacts on bone health, followed by a review of current literature as to its effects on mental health.

It is worth noting that osteoporosis, particularly osteoporotic fracture, may affect mental health and QOL. Osteoporotic fractures can lead to poorer QOL outcomes and negatively impact physical, social, financial, and psychological well-being (95-97). In regard to psychological well-being, osteoporosis can lead to feelings of anxiety, due to fear of falling or fear of fracture, and depression. It has been shown that anxiety and depression are comorbidities of osteoporosis (98), and osteoporotic fracture can cause reduced self-esteem and self-image, likely due to feelings of helplessness and loss of independence (99). All of these factors (loneliness, anxiety, depression, loss of independence, reduced self-esteem, loss of social role, etc.) may, in turn, contribute to disease exacerbation. Effective management of osteoporosis that reduces incidence of osteoporotic fracture (e.g., effective caregiver support) likely provides substantial indirect mental health benefit by preventing these negative outcomes. As 
TABLE 1 | Interactions of treatments for osteoporosis and psychological stress.

\begin{tabular}{|c|c|c|c|c|}
\hline Drug/therapy & Relevant target & Osteoporosis & Psychological stress & Other considerations \\
\hline Bisphosphonates & Osteoclasts/bone mineral density & + & $?$ & Potential improvement in mobility, which may improve QOL \\
\hline Statins & TGF $\beta$ pathway & + & $+/ ?$ & Cardiovascular impacts \\
\hline Denosumab & RANKL & + & $?$ & \\
\hline Teriparatide & Parathyroid hormone & + & $-/ ?$ & \\
\hline Estrogen/SERM & Multiple & + & $+/-$ & Long-term use could increase cancer risk \\
\hline Strontium ranelate & Bone mineral density & + & $?$ & \\
\hline SSRI & Serotonin & - & + & \\
\hline Benzodiazepines & GABA receptor & - & + & Cardiovascular impacts \\
\hline Beta-blockers & $\beta$-adrenergic antagonist & + & + & Cardiovascular impacts \\
\hline Barbiturates & GABA receptor & - & + & Addictive; No reversal agent \\
\hline Fish oil (EPA and DHA) & Unknown/multiple & + & $+/ ?$ & Cardiovascular impacts \\
\hline Calcium & Bone mineral density & + & $?$ & Kidney stone development \\
\hline Magnesium & Bone mineral density & + & $+/ ?$ & \\
\hline Vitamin D & Required for calcium absorption & + & $+/-$ & Kidney stone development \\
\hline Exercise & Multiple & + & + & Multiple health benefits \\
\hline
\end{tabular}

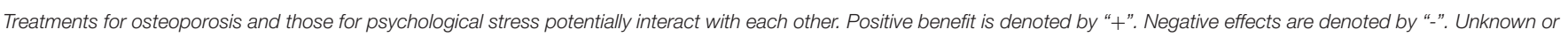
understudied effects are denoted by "?". Relevant targets in context of osteoporosis or stress are listed. Considerations that may have important clinical impacts are included.

described below, many treatments for osteoporosis may also have direct, biochemical effects on mental health.

\section{Bisphosphonates}

Bisphosphonates are antiresorptive agents that bind to hydroxyapatite crystals and become ingested by osteoclasts, where they suppress an enzyme involved in osteoclast-mediated bone resorption. This slows the rate of bone remodeling. In addition, they have been well-documented to reduce fracture risk [reviewed in Crandall et al. (100)]. However, bisphosphonates have negative effects on fracture repair, as they interfere with maturation of cartilaginous callus to mature bone (101). Furthermore, atypical femoral fractures and osteonecrosis of the jaw are two serious side effects of extended bisphosphonate use [reviewed in Black and Rosen (102)]. While bisphosphonates are effective at stalling bone loss, they cannot restore bone mass, as they are antiresorptive and not anabolic. Thus, they may be less effective for patients presenting with severe bone loss.

Bisphosphonates are often the first-choice treatment for osteoporosis, however, there are a limited number of studies, to date, that have examined potential implications of bisphosphonate treatment on mental health. Citraro et al. demonstrated that treatment of ovariectomized rats, a model of osteoporosis, with sodium alendronate had short-term benefit on anxiety and had beneficial impacts on motor performance (103). Reduced immobility, increased distance traveled, and increased mean velocity in behavioral assessments were shown in ovariectomized rats following 3 months of sodium alendronate treatment. However, benefit was not maintained following 6 months of treatment, and short-term benefit can likely be attributed to improved mobility. This suggests that bisphosphonate treatment may provide positive impact on QOL outcomes, due to improved mobility, and may have short-term benefit for anxiety and depression, particularly for patients with type I osteoporosis. An important consideration with bisphosphonate treatment, however, is non-compliance due to incidence of flu-like illness and gastrointestinal upset associated with their use, as well as complicated dosing schedules (104). Non-compliance may be further increased among patients with PTSD, therefore, additional follow-up may be necessary (105). Studies by Kastelan et al. have demonstrated that a monthly, rather than weekly, dosing schedule may also be beneficial toward improving compliance and QOL (106).

\section{Denosumab}

Denosumab is a monoclonal antibody to RANKL, a ligand expressed by osteoblasts that is necessary for the differentiation of osteoclasts. Denosumab sequesters RANKL and prevents its interaction with osteoclastic RANK, mimicking the natural function of osteoprotegerin (OPG). The resulting decrease in osteoclastogenesis is associated with significant increases in $\mathrm{BMD}$, which have been shown to continue for up to 10 years of treatment (107). Treatment with denosumab also decreases risk of hip, vertebral, and non-vertebral fractures (108). However, cessation of denosumab leads to a rapid rebound in bone turnover, which has raised concerns over multiple vertebral fractures $(109,110)$. Denosumab is administered as a subcutaneous injection every 6 months, which has been associated with higher compliance and greater patient satisfaction (111).

The effect of denosumab treatment on mental health is currently unknown. However, Suzuki et al. demonstrated that denosumab treatment altered levels of serum bone-related minerals in osteoporotic patients with rheumatoid arthritis, including alteration of magnesium levels, which is known to impact mental health (described below) (112). Further, recent reports are expanding our understanding of the role of the RANKL-RANK axis outside of the skeletal system [reviewed in 
Nagy and Penninger (113)]. RANKL is also expressed by T cells, which is thought to underlie the decrease in BMD associated with diseases of chronic $\mathrm{T}$ cell activation (114). RANKL-expressing T cells are known to home to the CNS, where they interact with RANK-expressing astrocytes and microglia $(115,116)$, cell types with an increasingly apparent role in the central response to chronic stress [reviewed in Calcia et al. (117)]. How denosumab affects immunomodulation of the CNS by RANKL-expressing $\mathrm{T}$ cells remains to be elucidated. There is also some evidence to suggest that activation of the sympathetic nervous system, commonly associated with chronic psychological stress, affects the peripheral expression of RANKL on osteoblasts $(118,119)$ and $\mathrm{T}$ cells (120). However, it is currently unknown how altered RANKL expression modulates the efficacy of denosumab in individuals with chronic psychological stress.

\section{Estrogen Replacement Therapy/Selective Estrogen Receptor Modulators (SERMs)}

Estrogen replacement can prevent postmenopausal bone loss and reduce fracture risk (121-125). The lack of estrogen in postmenopausal women causes dysregulation of bone cell differentiation, alters osteoblast/osteoclast activity, and induces osteoblast and osteocyte apoptosis, thereby leading to increased bone turnover, with a net effect of resorption exceeding formation (126-128). This is due to increased secretion of proinflammatory factors, such as IL-1 IL-6, and TNF- $\alpha$, as well as estrogen's regulatory role in osteoclast receptor signaling, including RANKL and OPG (129-133). In addition, estrogen loss leads to decreased production of IGF-1, transforming growth factor $\beta$ (TGF $\beta$ ), and COL1, all of which are involved in stimulating osteoblast differentiation and activity. Estrogen replacement therapy, in effect, reverses these changes (134137). However, the anabolic effects of estrogen on bone are dependent on preparation, dose, and route of administration (138). Likewise, estrogen plays a significant role in many tissues throughout the body, so systemic replacement of estrogen creates a complex clinical scenario. For example, a study by the Women's Health Initiative found that estrogen replacement had beneficial effects on fracture and colon cancer risk, but also increased incidence of cardiovascular events, strokes, pulmonary embolisms, and invasive breast cancers (139). Thus, although clearly effective, these systemic effects have lessened enthusiasm for estrogen replacement therapy as the first-line treatment option for osteoporosis (140).

Similarly, selective estrogen receptor modulators (SERMs) have been studied for their impacts on BMD and fracture risk. SERMs are compounds that interact with estrogen receptors and, like estrogen replacement, have broad systemic effects. Raloxifene has been widely used for treating osteoporosis, although its effects on BMD are modest, and it appears to only impact vertebral fractures $(141,142)$. Long-term use of raloxifene also decreased breast cancer risk, but increased risk of thromboembolic events $(108,143-145)$. Thus, as with estrogen replacement, SERMs are unlikely to be the gold standard treatment option for osteoporosis, but may be particularly beneficial for women with a strong family history of estrogen receptor-positive invasive breast cancer (146).
Along with impacting a range of tissues, estrogen has profound effects on mental health and is a known regulator of the stress response (147-149). Postmenopausal estradiol therapy provides protective effects against stress-induced cognitive effects, particularly working memory (150). Estrogen also positively impacts distribution of serotonin receptors, suggesting a role for estrogen in mood regulation $(151,152)$. Glover et al. found that low circulating estrogen levels are associated with higher fear-potentiated startle and fear extinction deficits in women with PTSD (153). Therefore, low levels of estrogen may play a role in PTSD by decreasing fear inhibition. Though several studies have demonstrated a positive impact of estrogen on mental health, negative effects of estrogen on brain activity and memory formation have also been observed. Shansky et al. showed that estrogen treatment impacted activity in the medial prefrontal cortex, resulting in increased sensitivity to working-memory impairment caused by pharmacologic and restraint stressors, possibly through regulation of the alpha-2a adrenergic receptor (154). Dysfunction of the medial prefrontal cortex is associated with stress-related disorders, including major depressive disorder and PTSD. Estrogen may also lead to increased intrusive memories, thereby influencing memory of emotionally arousing events (155). Further, estrogen has been shown to play a role in the pathophysiology of migraines, which are linked to depression, anxiety, abuse, and PTSD (156). Thus, estrogen plays a major and complex role in the stress response and may have both positive and negative effects on different areas of the brain. Estrogen's effects on cognition are likely further complicated by age and hormone status of the patient. It is of note that raloxifene does not appear to affect memory or cognition, and, thus, may be a better treatment option than estrogen replacement for women with a history of mental health disorders (145).

\section{Statins}

Statins have been prescribed for the treatment of cardiovascular disease for decades, but are just beginning to be investigated for their anabolic impact on bone [reviewed in Ruan et al. (157)]. Statins have been shown to influence bone remodeling through the BMP pathway and may inhibit osteoclast differentiation through increased BMP-2 expression (158). Statins may also regulate the RANK pathway to inhibit osteoclastogenesis. Bone formation may be promoted by statins through inhibition of osteoblast apoptosis mediated by Smad3 deletion via the TGF $\beta$ pathway. Currently, simvastatin and atorvastatin have been shown to have clinical efficacy (increased BMD) in the treatment of osteoporosis, while trials with other statins, such as pravastatin and rosuvastatin, failed to meet study primary outcomes of reduced fracture risk [reviewed in Wang et al. (159)]. Statin bioavailability in bone is low and may explain the lack of full efficacy despite the strong role in bone anabolism demonstrated in animal models and basic laboratory studies $(160,161)$. However, additional studies and efforts to improve bioavailability should be pursued as a result of the promising outcomes of early clinical and basic studies.

Statins may have beneficial effects on depression and anxiety. Simvastatin had an anti-depressant effect in a chronic mild stress 
model (162). However, data is conflicting with respect to patient benefit $(163,164)$. Epidemiological data suggests a potential positive effect, especially as an adjunctive therapy [reviewed in Salagre et al. (165)]. Statins also have anti-inflammatory and anti-oxidant functions, which may be beneficial for both stress-related pathologies and osteoporosis [reviewed in Bedi et al. (166)]. However, their use for treating psychological stress or osteoporosis concurrent with psychological stress requires additional examination.

\section{Strontium Ranelate}

Strontium ranelate is a divalent cation, similar to calcium, and can be administered daily in powder form to treat osteoporosis. Although its effects are weak, it is approved in Europe for treatment of osteoporosis in postmenopausal women and in men at high risk of vertebral and hip fractures who cannot use other pharmacological agents, such as bisphosphonates (16). It results in large increases in $\mathrm{BMD}$, but this is partially due to the heavier strontium ions physically replacing calcium ions within the hydroxyapatite. In postmenopausal women with established osteoporosis, 4-year treatment with strontium ranelate reduced incidence of vertebral fractures by $\sim 40 \%$ and non-vertebral fractures by $16 \%$, while hip fractures were found to be reduced only after post-hoc analysis of a high-risk patient subgroup (167, 168 ). While a potentially effective antiresorptive agent, strontium ranelate may be associated with increased risk of cardiovascular events and, thus, patients must be closely monitored (169).

There are minimal studies that have examined the direct effect of strontium ranelate on mental health. However, improved QOL outcomes associated with its use may offer benefit to those experiencing psychological stress. For example, oral administration of strontium ranelate in postmenopausal women with established vertebral osteoporosis resulted in prevention of QOL impairment compared to placebo group, with clear improvement in emotional and physical dimension scores (170). In addition, a 2008 multicenter trial in Russia analyzed the effect of 1-year administration of strontium ranelate on BMD of patients with postmenopausal osteoporosis. It was found that strontium ranelate increased lumbar vertebra $\mathrm{BMD}$, inhibited local tissue-mediated bone resorption markers, and resulted in improved QOL outcomes, with patients reporting better motility, lowered rates of depression, and improved self-assessments (171). While promising, further studies are needed to determine the impacts of strontium ranelate on mental health and whether or not it may serve as a more suitable treatment option for osteoporotic patients with a history of mental health disorder.

\section{Teriparatide}

Teriparatide is a recombinant form of PTH, consisting of the bioactive N-terminal 34 amino acids. PTH is involved in regulation of serum calcium levels and is a stimulator of both bone formation and bone resorption. Teriparatide is the only FDA-approved anabolic bone agent for treating osteoporosis, but is, currently, cost-prohibitive $(35,172)$. Daily or weekly subcutaneous injections of teriparatide were shown to increase both spine and hip BMD (173). Neer et al. demonstrated that a $20 \mu \mathrm{g} /$ daily dose of teriparatide resulted in $\sim 70 \%$ reduction in vertebral fractures and $\sim 50 \%$ reduction in nonvertebral fractures in women with low BMD and a previous history of vertebral fractures over a 21 -month treatment period (174). However, teriparatide did not reduce hip fracture risk. Teriparatide is associated with a number of negative side effects, including nausea, headache, hypercalcemia, and musculoskeletal pain. In addition, benefits of teriparatide are quickly lost after discontinuation, and it is only approved for up to 2 years of use (102). Importantly, it has also been shown that co-therapy with teriparatide and alendronate does not provide advantage over monotherapy (175).

In regard to mental health effects, common symptoms of hyperparathyroidism overlap with those of psychological stress-associated mental health disease, including fatigue, anxiety, insomnia, and depression. The molecular, cellular, and biochemical mechanisms behind the relationship between PTH and mental health are not known. Recently, however, PTH levels were shown to negatively correlate with plasma corticosterone levels after acute restraint stress (176). In addition, a significant reduction in parathyroid hormone receptor 1 (PTHR1) levels in both the kidney and thyroid was observed in rats exposed to chronic (28-day) daily restraint stress. This potential link is supported by clinical data, which demonstrated that teriparatide resulted in increased plasma and urinary cortisol following sustained treatment (6 months-1 year) (177). These studies suggest clinical considerations should be made regarding the potential impact of teriparatide use on cortisol levels in osteoporotic patients with PTSD, depression, or anxiety.

\section{Psychological Stress Treatments}

As described above, it is clear that osteoporosis, particularly osteoporotic fracture, and associated treatments may have substantial mental health impacts. Mental health disorders may also, in turn, have significant impact on bone health. Anxiety has been reported to contribute to lower hip BMD (178). Several studies have shown that depression is a predictive factor for osteoporosis and fracture development (179-181). In addition, pharmacological interventions targeted at improving mental health, particularly in patients with major depressive disorder or PTSD diagnoses, may impact bone health. In the subsections below, we describe commonly prescribed medications for PTSD and depression and then review current literature indicating impacts of these agents on bone health.

\section{Selective Serotonin Reuptake Inhibitors (SSRIs)}

Selective-serotonin reuptake inhibitors (SSRIs) have become a first-line treatment for patients with moderate to severe depressive disorders, as they are generally considered safe, welltolerated, and associated with minimal severe side effects (182). SSRIs function by inhibiting serotonin (see section Serotonin) reuptake by the presynaptic neuron, thereby maintaining higher levels of serotonin in the synapse and increasing postsynaptic neurotransmission. As a result of this inhibition, there is a resultant increase in extracellular concentrations of serotonin in both the brain and periphery. In addition, SSRIs are most highly concentrated in the bone marrow, thus raising the concern as to their impacts on bone metabolism (183). Interestingly, 
SSRIs appear to exert a temporally regulated dual-effect on bone. Short-term SSRI administration results in elevated systemic serotonin levels, but these levels are reduced by about $50 \%$ over a longer treatment period [reviewed in Ducy and Karsenty G (81)]. In a rigorous study by Ortuno et al., fluoxetine was shown to act on bone remodeling via two distinct mechanisms in mice. When used for $<3$ weeks, fluoxetine acts peripherally to cause anti-resorptive effects by directly impairing osteoclast differentiation and function through a serotonin-reuptakeindependent mechanism that is dependent on intracellular $\mathrm{Ca}^{2+}$ levels and the transcription factor, Nfatcl. In addition, these effects were reversible, thus ruling out cell death as the reason for the observed anti-resorptive effects. No effect of fluoxetine was observed on osteoblasts. However, when fluoxetine was given to mice for 6 weeks, it triggered a brain serotonin-dependent rise in sympathetic output that increased bone resorption sufficiently to counteract its local anti-resorptive effect, which led to a net effect of impaired bone formation and bone loss. Hypothalamic extracts from mice treated for 6 weeks with fluoxetine showed significantly lower levels of $\mathrm{p}$-CREB, a downstream mediator of serotonin signaling through Htr2c. The study also found that it was possible to neutralize this long-term effect of fluoxetine treatment through co-treatment with the beta-blocker, propranolol, which leaves the localized peripheral effect intact and prevents fluoxetine-induced bone loss (184).

In accordance with these findings, clinical studies illustrate that, with chronic usage of commonly prescribed SSRIs, bone health is negatively impacted. In numerous studies, SSRIs have been found to increase risk for secondary osteoporosis, lower $\mathrm{BMD}$, and increase incidence of both hip and vertebral fractures (185-192). The direct mechanisms by which SSRIs impact bone health, particularly in humans, are still not wholly understood, particularly due to temporal and location-specific effects of serotonin. However, a promising potential treatment option may be LP533401, an inhibitor of Tph1, that does not cross the bloodbrain barrier, thus will not affect synthesis of brain serotonin. LP533401 has been shown in a Phase II clinical trial to not exhibit significant toxicity or side effects in patients being treated for irritable bowel syndrome (193). In rats, LP533401 administration once daily by oral gavage for up to 6 weeks resulted in full rescue of osteoporosis in ovariectomized rodents in a dose-dependent manner $(194,195)$. Taken together, these studies would suggest that it is important to consider a patient's history of SSRI use when treating osteoporosis, as any benefit received from an osteoporotic drug, such as a bisphosphonate, could be countered by concurrent SSRI use [reviewed in Haney et al. (196)].

\section{Benzodiazepines (anxiolytics)}

Benzodiazepines are another commonly prescribed treatment for psychological stress, especially as a second-line or adjunctive medication. These drugs enhance the signaling of the neurotransmitter, gamma-Aminobutyric acid (GABA), through GABA receptors, and may also increase dopamine signaling to reduce anxiety that is often associated with stress. Benzodiazepines are central nervous system depressants and, thus, have sedating effects.
Benzodiazepines have been shown to have significant negative impact on bone health, primarily due to increased fall risk (197). Benzodiazepines have also been shown to decrease osteoblast differentiation through benzodiazepine-like receptors. BMD may also be reduced as a result of benzodiazepine treatment, and their use has been associated with increased ALP, reduced serum levels of vitamin D [reviewed in Fan et al. (198)], and increased levels of prolactin, which, in turn, results in decreased estrogen (199). These studies strongly suggest that benzodiazepines be prescribed with caution among those at risk for development of osteoporosis, and lifestyle modifications and supplementation as adjunctive therapies warrant consideration in these patients.

\section{Barbiturates}

Barbiturates, derived from barbituric acid, are a class of central nervous system depressants and are classified as anti-epileptic drugs. Barbiturates are GABA receptor agonists, exerting their effect by blocking transmembrane receptors for the primary excitatory neurotransmitter in the central nervous system, glutamate. The resulting activation of inhibitory GABA signaling coupled with inhibition of excitatory neurotransmitters causes sedation. These drugs are highly addictive and do not have a reversal agent in the case of overdose. Therefore, barbiturates are not as widely prescribed today as they have been in the past. However, these drugs are still prescribed for treatment of anxiety, seizures, migraine headaches, and in the elderly as sleep aids.

Barbiturates are detrimental to bone due to impacts on calcium and vitamin D metabolism and absorption. Although the negative effects of barbiturates are likely multifactorial and complex (200), perhaps the most recognized mechanism is through increased cytochrome p-450 enzymatic activity, which results in production of an inactive form of vitamin D, thereby leading to a reduction in calcium absorption from the gastrointestinal tract. Reduced vitamin D and calcium levels stimulate production of PTH and perpetuate bone loss due to calcium resorption from bone $(201,202)$. Due to their significant effects on bone resorption, use of barbiturates has been noted as a cause of secondary osteoporosis. As with other CNS depressants, barbiturate use is associated with increased risk of fracture due to an increased fall risk resulting from gait disturbances. Thus, due both to the risk of addiction and implication in osteoporosis, as well as elevated fracture and fall risk, alternatives to barbiturates for the treatment of psychological stress may be preferred.

\section{Beta-Blockers}

Beta-blockers act to inhibit $\beta$-adrenergic signaling and are commonly prescribed for the treatment of hypertension. More recently, beta-blockers, such as propranolol, have been prescribed for other conditions, including anxiety. The use of beta-blockers for PTSD has also been suggested, with the goal of preventing detrimental memory relapse of traumatic events [reviewed in Roque (203), Burbiel (204)]. However, due to concerns regarding potential negative impact on depression, these medications are not necessarily considered front-line treatments for psychological stress-associated mental health disease.

Given the impact of catecholamines on bone health (discussed above), it is not surprising that beta-blockers may have beneficial 
impacts on osteoporosis (205) and have been shown to reduce fracture risk by as much as $50 \%$. In a study of men over the age of 55, long-term ( $>5$ years) beta-blocker use was associated with increased maxillary BMD compared to those on calcium channel blockers for hypertension (206). In a U.K. study, betablocker treatment was associated with reduced fracture risk (207). This was also demonstrated in an Australian study, in which women on beta-blockers were shown to have decreased fracture risk and increased BMD of the hip and ultradistal forearm (208). In vitro studies suggest that the positive impact of beta-blockers on bone health may be due to promotion of bone formation by osteoblasts, increased osteoblast numbers, decreased osteoclast numbers, and impairment of osteoclastmediated bone resorption (209).

\section{LIFESTYLE MODIFICATION AND DIETARY SUPPLEMENTS}

In this section, we provide a perspective outlook on lifestyle modifications and dietary supplements that may have beneficial effects on bone health (210) and may reduce psychological stress (211). For example, it has been suggested that the Mediterranean diet may have positive impacts on bone health, whereas the modern Western diet causes a state of low-grade chronic inflammation that promotes osteoporosis (212214). A movement toward complimentary, alternative and integrative medicine has provided insight into the benefits of adjunctive and naturopathic remedies. Calcium and vitamin D supplementation have well-recognized benefits toward improved bone health and reducing osteopenia. However, their impacts on psychological stress are less well-studied. Other alternative therapies that have been gaining attention include magnesium supplementation and fish oil/omega-3 supplementation. The benefits of exercise in promoting overall health are well-recognized. Recent studies regarding several lifestyle modifications and dietary supplements and their effects on bone health and psychological stress are described below. These alternatives may offer complementary benefit with reduced risk compared to traditional pharmacological intervention, and, therefore, warrant additional study toward potential impact on patient outcome for those with, or at high risk for, osteoporosis and concurrent psychological stressassociated mental health disorders. In the subsections below, literature supporting alternative or adjunctive therapies are discussed. First, the literature indicating effects on bone health are described, followed by a review of the literature indicating impact on mental health.

\section{Exercise}

Besides obvious beneficial effects on muscle mass, weight-bearing and resistance exercises can lead to increases in BMD (215). Although this impact may be more beneficial at a young age, some studies have shown that exercise increases BMD in postmenopausal women $(216,217)$. Longitudinal studies using high-resolution computed tomography scans have shown that regular physical activity improves skeletal microarchitecture
(218). Further, exercise and balance can limit fall risk (102). The converse is also true, in that low levels of physical activity are associated with bone loss and $>2$-fold risk of fracture $(219,220)$. However, robust data is still lacking on whether there are any beneficial effects of long-term exercise on fracture susceptibility.

It is well-established that regular exercise can improve mental health. Participation in exercise programs has been shown to improve symptoms in patients with anxiety-, stress-, and trauma-related disorders, with positive effects lasting beyond the scope of the training program (221-224). In some cases, exercise therapy was more effective in reducing anxiety than traditional forms of therapy, including psychotherapy and pharmacotherapy $(222,225,226)$. The benefits of short- and long-term aerobic exercise on overall mental health and function are multifold. On a biochemical level, exercise has been shown to reverse some of the neurological changes induced by exposure to psychosocial and/or physical stressors, including release of hippocampal corticosterone, decreased neurogenesis, and impaired hippocampal-dependent behaviors, such as learning and memory (227-230). In animal models of stress, both forced and voluntary exercise interventions have been shown to restore neuronal differentiation in the hippocampus (231, 232), increase levels of hippocampal brain-derived neurotrophic factor (BDNF) (233-235), and restore cognitive function (233, 236). There is also evidence that exercise-induced neurochemical changes, including increased production of hippocampal BDNF and altered hippocampal glucocorticoid receptor levels, may be protective against the stress response (237-239). On a psychological level, exercise may act as an interoceptive exposure (240, 241), in which patients with PTSD and anxiety-related disorders are sensitized to feared somatic sensations $(242,243)$. Alternatively, exercise may produce its anxiolytic effect by offering a distraction from distressing thoughts $(244,245)$ and/or inducing neurochemical changes, such as increased endorphin production (246). The biochemical mechanisms by which exercise alleviates symptoms in patients with anxiety and PTSD have not been fully elucidated and require further investigation.

\section{Calcium and Vitamin D}

Nutrition and intake of appropriate levels of vitamins and minerals play a key role in maintenance of a healthy skeleton. In regard to osteoporosis, calcium and vitamin $\mathrm{D}$ supplementation have been the most studied to date. The Women's Health Initiative conducted a large randomized trial involving more than 36,000 postmenopausal women to determine the efficacy of $1,000 \mathrm{mg}$ of calcium combined with $400 \mathrm{IU}$ of vitamin D supplementation daily. It was found that this combination did not significantly impact risk of hip fracture, although posthoc analysis demonstrated benefits for women age 60 years of age or older and those who adhered most strictly to the treatment schedule (247). In contrast, a 2016 meta-analysis of randomized controlled trials found a significant $15 \%$ reduced risk of total fractures and a 30\% reduced risk of hip fractures with calcium and vitamin D supplementation (248). However, there has been no evidence, to date, that vitamin $\mathrm{D}$ supplementation alone reduces fracture risk, although it may reduce fall risk (249). Effects of supplemental calcium alone on fracture risk 
are still unknown, as no large-scale, randomized trials have been conducted (102). In addition, vitamin D and calcium supplementation were, not surprisingly, shown to increase risk of kidney stone development by $17 \%$ (247). Thus, at this time, vitamin $\mathrm{D}$ and/or calcium supplementation alone is not considered an appropriate treatment for osteoporosis.

In regard to mental health, several studies have examined the effects of vitamin D and calcium. Vitamin D is known to play a role in depression (250-252), and vitamin D receptors are present in multiple brain regions (253). Further, recent studies have begun to demonstrate a relationship between anxiety and serum levels of vitamin D (254). This may impact quality of life, particularly in postmenopausal women at increased risk of osteoporosis $(255,256)$. Vitamin D has also been shown to increase synthesis of neurotransmitters, including dopamine and norepinephrine, in rats (257). However, in a large-scale randomized, double-blinded US trial, no relationship was found between vitamin $\mathrm{D} /$ calcium supplementation and depression in over 36,000 postmenopausal women (258). In contrast, a Norwegian randomized, double-blind controlled trial found that weekly administration of vitamin $\mathrm{D}$ for 1 year in normal, healthy adults resulted in improved scores for depression compared to placebo (259). In a Korean study, low-dietary calcium was found to be associated with increased depression in middle-aged women (260). In women with premenstrual syndrome, supplementation with $500 \mathrm{mg}$ of calcium carbonate twice daily for 3 months resulted in improvements in parameters assessing early tiredness, appetite changes, and depressive symptoms (261). There are also studies to suggest that calcium supplementation can be used to mitigate symptoms of postpartum depression (262). Thus, there is accumulating evidence of the beneficial effects of vitamin D and/or calcium supplementation on depression.

\section{Magnesium}

Magnesium is the fourth most abundant cation in the body and is involved in cardiovascular, bone, and brain health, as well as maintenance of homeostasis $(263,264)$. Supplementation with magnesium is generally well-tolerated with limited side effects. For bone, magnesium supplementation has been less well studied than calcium and/or vitamin D. However, bones store approximately $60 \%$ of total body magnesium, and its release is dependent upon bone resorption (265). In rats, it has been shown that decreased dietary magnesium leads to a reduction in vitamin D, ALP, and OCN levels, as well as decreased bone volume and trabecular thickness (266). Tucker et al. demonstrated that magnesium intake was associated with increased BMD at one hip site for men and women and in the forearms of men (267). In a 2014 Women's Health Initiative study, it was found that postmenopausal women who consumed $>422.5 \mathrm{mg}$ of magnesium had slightly higher (2-3\%) BMD than women who consumed $<206.5 \mathrm{mg}$ of magnesium daily. In addition, magnesium consumption correlated with increased physical activity, but also increased fall risk (268). A 2017 study demonstrated that dietary magnesium intake led to a $27 \%$ decrease in fracture risk (269). Thus, maintaining appropriate levels of magnesium appears to be beneficial in the maintenance of bone integrity.

Magnesium supplementation has been suggested for its anxiolytic effects and has shown promising results in clinical studies. However, additional examination is required to develop appropriate treatment recommendations [reviewed in Boyle et al. (270)]. Low magnesium intake (271) and low serum levels of magnesium have been associated with depression [reviewed in You et al. (272)]. Several studies have also demonstrated positive effects of magnesium supplementation for depression $(273,274)$. Magnesium has also been used to improve sleep, especially among those with magnesium deficiency. Mechanistic studies of magnesium supplementation on depression have been limited. However, in a model of chronic mild stress, it was demonstrated that magnesium may exert its anxiolytic and anti-depressive effects in part by acting as a GABA agonist and as an inhibitor of $\mathrm{N}$-methy-D-aspartate receptor (NMDAR) (275). Based on these positive effects on mental health and bone integrity, as well as limited negative side effects, magnesium supplementation may serve as a beneficial supplement for osteoporotic patients with a history of mental health disorder.

\section{Omega-3 Fatty Acids}

Polyunsaturated fatty acids, including eicosapantaenoic acid (EPA) and docosahexaenoic acid (DHA), are commonly contained in fish oil supplements and fatty fish, such as salmon, tuna, mackerel, and sardines. The ratio of these fatty acids varies across fish oil supplements and can have significant impact on effect and balance of these omega- 3 and omega- 6 fatty acids in the body. This balance is critical toward the beneficial anti-inflammatory effects of fatty acid supplementation. Due to these anti-inflammatory effects, there have been a handful of studies examining the impacts of fatty acids on bone health [reviewed in El-Sayed and Ibrahim (276)]. Using bone marrowderived macrophages, Kim et al. demonstrated that DHA led to suppression of macrophage colony-stimulating factor (M$\mathrm{CSF}$ )-induced proliferation of osteoclast precursors. This effect was likely mediated through decreased Akt activation and downregulated cyclin D1 and D2 expression. In addition, DHA led to increased apoptosis in mature osteoclasts (277). In rats, a diet supplemented with chia seeds, which are fatty acidrich, was shown to increase BMD in the tibia (278). LavadoGarcia et al. observed a similar effect, with long-chain omega-3 polyunsaturated fatty acid intake contributing to an increase in BMDs in the hips and lumbar spine of normal and osteopenic, but not osteoporotic, Spanish women (279). In a randomized, double-blind, placebo-controlled trial, Dong et al. reported that omega-3 polyunsaturated fatty acid supplementation led to decreased bone turnover by decreasing serum levels of bonespecific ALP and OCN over time (280). However, it was stated that higher doses and a longer duration needed to be tested before a definitive statement could be made as to the effects of fatty acids on bone metabolism. In a systemic review and metaanalysis, Shen et al. suggest that the primary impact of omega-3 fatty acids on bone is a reduction in serum OCN (281). However, there is still a lack in mechanistic understanding of how omega-3 fatty acids may be mediating these effects on bone, particularly 
since even just one fatty acid can trigger multiple independent pathways (282).

Depression and anxiety have been associated with reduced levels of polyunsaturated fatty acids $(283,284)$. Accordingly, several studies have demonstrated a positive effect of fatty acid supplementation [reviewed in Burhani and Rasenick (285)]. One study in rats comparing the effects of EPA and DHA supplementation demonstrated increased anxiolytic effects of EPA (286). Another study demonstrated anti-depressant effects of fish oil supplementation in rats subjected to chronic unpredictable mild stress (287). Fish oil supplementation may also improve the physiological symptoms of psychological stress. Fish oil supplementation has been shown to reduce the effects of mental stress (serial subtraction exercises) on heart rate, calf vascular conductance, and muscle sympathetic nerve activity (288). In contrast, a more recent study demonstrated no benefit of EPA supplementation on perceived psychological stress (289). Therefore, while studies have been promising regarding the use of omega-3 supplementation for treatment of psychological stress, including depression, anxiety, and PTSD, continued research is needed to determine the appropriate type of supplementation, dose, and application. Continued mechanistic studies are needed, but, to date, studies have suggested these supplements impart anti-inflammatory action and modification of neurotransmitter signaling through membrane and G-protein mechanisms [reviewed in Burhani and Rasenick (285)]. Overall, studies have shown promising benefit to multiple pathologies without significant negative impact. As such, fatty acid supplementation may warrant recommendation for concurrent osteoporosis and psychological stress.

\section{CONCLUSIONS}

Together, the studies reviewed above suggest that, while osteoporosis and psychological stress occur via differing mechanisms, there are several potential molecular links that exist between a pathological response to stress and the development of bone disease. Although not a comprehensive list, these may include dysregulation of the HPA-axis and SAM pathway, inflammatory pathways, IGF signaling, estrogen, serotonin, GABA, and RANKL (Figures 1, 2). Consequently, an in-depth understanding of the mechanisms that regulate and intersect

\section{REFERENCES}

1. Zigdon-Giladi H, Rudich U, Michaeli Geller G, Evron A. Recent advances in bone regeneration using adult stem cells. World J Stem Cells. (2015) 7:630-40. doi: 10.4252/wjsc.v7.i3.630

2. Bonewald LF. The amazing osteocyte. J Bone Miner Res. (2011) 26:229-38. doi: 10.1002/jbmr.320

3. Kanis JA. Assessment of fracture risk and its application to screening for postmenopausal osteoporosis: synopsis of a WHO report. WHO Study Group. Osteoporos. (1994) 4:368-81. doi: 10.1007/BF01622200

4. America's Bone Health: The State of Osteoporosis and Low Bone Mass in Our Nation. The Foundation; (2002) 110 p.

5. Simpson AH, Murray IR. Main differences in osteoporotic fracture models: which should I use? Injury. (2016) 47 (Suppl 1):S15-20. doi: 10.1016/S0020-1383(16)30004-3 stress and bone health is needed to determine risk and treatment recommendations.

In addition, the pharmacological therapies used for mental health disorders and osteoporosis may have interacting effects (Table 1) that should be carefully considered in making treatment recommendations toward the most beneficial effect. These interactions are likely highly complex and influenced by a number of patient-specific risk factors, including lifestyle, genetics, epigenetics, and diet. Thus, there is a need for further basic and clinical research to determine the significance of chronic psychological stress on bone health. The multifactorial nature of diseases in treatment, lifestyle recommendations, in terms of making informed personalized medicine decisions should also be considered. Alternative or adjunctive therapies, such as lifestyle modification and dietary supplementation, may represent a novel approach to mitigating the effect of concurrent chronic psychological stress and osteoporosis, but further study is needed to examine the potential benefit of these options in this context. Overall, the interaction of psychological stress and osteoporosis is an important example of the need for additional research examining the broad, whole-health effects of chronic psychological stress on disease and the need for further study of the application of lifestyle modifications toward a personalized medicine approach.

\section{AUTHOR CONTRIBUTIONS}

RK and LM: conception and design, drafting, and revising of the manuscript. NJ, SS, and AL: drafting and revising of the manuscript. All authors read and approved the final manuscript.

\section{FUNDING}

Development of this manuscript was supported by the Biomedical Laboratory Research and Development Program of the Department of Veterans Affairs (VA Merit Award to AL, BX000333).

\section{ACKNOWLEDGMENTS}

The authors would like to thank Kirsten Kelly for her aid and expertise in generating artwork.
6. Aubin JE, Bonnelye E. Osteoprotegerin and its ligand: a new paradigm for regulation of osteoclastogenesis and bone resorption. Osteoporos. (2000) 11:905-13. doi: 10.1007/s001980070028

7. Manolagas SC, Jilka RL. Bone marrow, cytokines, and bone remodeling. Emerging insights into the pathophysiology of osteoporosis. N Engl J Med. (1995) 332:305-11. doi: 10.1056/NEJM199502023320506

8. Rosenzweig A, Pignolo RJ. Osteobiology of Aging. In: Pignolo RJ, Keenan MA, Hebela NM, editors. Fractures in the Elderly: A Guide to Practical Management. Totowa, NJ: Humana Press (2011). p. 3-37.

9. Ucer S, Iyer S, Kim H-N, Han L, Rutlen C, Allison K, et al. The effects of aging and sex steroid deficiency on the murine skeleton are independent and mechanistically distinct. J Bone Miner Res. (2017) 32:56074. doi: 10.1002/jbmr.3014

10. Liu W, Qi M, Konermann A, Zhang L, Jin F, Jin Y. The p53/miR-17/Smurf1 pathway mediates skeletal deformities in an age-related model via 
inhibiting the function of mesenchymal stem cells. Aging. (2015) 7:205-18. doi: 10.18632/aging.100728

11. Compston J. Glucocorticoid-induced osteoporosis: an update. Endocrine. (2018) 61:7-16. doi: 10.1007/s12020-018-1588-2

12. Briot K, Roux C. Glucocorticoid-induced osteoporosis. RMD Open. (2015) 1:e00(0014) doi: 10.1136/rmdopen-2014-000014

13. Elefteriou F, Campbell P, Ma Y. Control of bone remodeling by the peripheral sympathetic nervous system. Calcif Tissue Int. (2014) 94:140-51. doi: 10.1007/s00223-013-9752-4

14. Sinaki M. Musculoskeletal challenges of osteoporosis. Aging Milan Italy. (1998) 249-62. doi: 10.1007/BF03339659

15. Cheung WH, Miclau T, Chow SK-H, Yang FF, Alt V. Fracture healing in osteoporotic bone. Injury. (2016) 47 (Suppl 2):S21-26. doi: 10.1016/S0020-1383(16)47004-X

16. Tabatabaei-Malazy O, Salari P, Khashayar P, Larijani B. New horizons in treatment of osteoporosis. DARU J Pharm Sci. (2017) 25:2 doi: 10.1186/s40199-017-0167-z

17. Kelly RR, Mcdonald LT, Pellegrini VD, Cray JJ, Larue AC. Identification of circulating murine CD34+OCN+ cells. Cytotherapy. (2018). 20:1371-80. doi: 10.1016/j.jcyt.2018.07.004

18. Benisch P, Schilling T, Klein-Hitpass L, Frey SP, Seefried L, Raaijmakers $\mathrm{N}$, et al. The transcriptional profile of mesenchymal stem cell populations in primary osteoporosis is distinct and shows overexpression of osteogenic inhibitors. PLoS ONE. (2012) 7:e4(5142) doi: 10.1371/journal.pone.0045142

19. Phetfong J, Sanvoranart T, Nartprayut K, Nimsanor N, Seenprachawong K, Prachayasittikul V, et al. Osteoporosis: the current status of mesenchymal stem cell-based therapy. Cell Mol Biol Lett. (2016) 21:12 doi: 10.1186/s11658-016-0013-1

20. Baum A. Stress, intrusive imagery, and chronic distress. Health Psychol. (1990) 9:653-75. doi: 10.1037/0278-6133.9.6.653

21. Miller GE, Murphy MLM, Cashman R, Ma R, Ma J, Arevalo JMG, et al. Greater inflammatory activity and blunted glucocorticoid signaling in monocytes of chronically stressed caregivers. Brain Behav Immun. (2014) 41:191-9. doi: 10.1016/j.bbi.2014.05.016

22. Yang L, Zhao Y, Wang Y, Liu L, Zhang X, Li B, et al. The effects of psychological stress on depression. Curr Neuropharmacol. (2015) 13:494504. doi: 10.2174/1570159X1304150831150507

23. Association AP. Diagnostic and Statistical Manual of Mental Disorders (DSM$\left.5^{\circledR}\right)$. Arlington, VA: American Psychiatric Pub (2013).

24. Administration UD of VA Veterans Health. PTSD in Iraq and Afghanistan Veterans - Public Health. Available from: https://www.publichealth.va.gov/ epidemiology/studies/new-generation/ptsd.asp(accessed December 6, 2018).

25. Reisman M. PTSD treatment for veterans: what's working, what's new, and what's next. Pharm Ther. (2016) 41:623-34.

26. Chrousos GP. Stress, chronic inflammation, and emotional and physical well-being: concurrent effects and chronic sequelae. J Allergy Clin Immunol. (2000) 106(5 Suppl):S275-91. doi: 10.1067/mai.2000.110163

27. Cohen S, Janicki-Deverts D, Doyle WJ, Miller GE, Frank E, Rabin BS, et al. Chronic stress, glucocorticoid receptor resistance, inflammation, and disease risk. Proc Natl Acad Sci USA. (2012) 109:5995-9. doi: 10.1073/pnas.1118355109

28. El-Gabalawy R, Blaney C, Tsai J, Sumner JA, Pietrzak RH. Physical health conditions associated with full and subthreshold PTSD in U.S. military veterans: results from the National Health and Resilience in Veterans Study. J Affect Disord. (2018) 227:849-53. doi: 10.1016/j.jad.2017.11.058

29. Huang WS, Hsu JW, Huang KL, Bai YM, Su TP, Li CT, et al. Post-traumatic stress disorder and risk of osteoporosis: A nationwide longitudinal study. Stress Health J Int Soc Investig Stress. (2018) 34:440-5. doi: 10.1002/smi.2806

30. Paratz ED, Katz B. Ageing Holocaust survivors in Australia. Med J Aust. (2011) 194:194-7. doi: 10.5694/j.1326-5377.2011.tb03771.x

31. Foertsch S, Haffner-Luntzer M, Kroner J, Gross F, Kaiser K, Erber M, et al. Chronic psychosocial stress disturbs long-bone growth in adolescent mice. Dis Model Mech. (2017) 10:1399-409. doi: 10.1242/dmm.030916

32. Bottaccioli AG, Bottaccioli F, Minelli A. Stress and the psyche-brain-immune network in psychiatric diseases based on psychoneuroendocrineimmunology: a concise review. Ann N Y Acad Sci. (2018) 1437:31-42. doi: 10.1111/nyas.13728
33. Dhabhar FS. Effects of stress on immune function: the good, the bad, and the beautiful. Immunol Res. (2014) 58:193-210. doi: 10.1007/s12026-014-8517-0

34. Heidt T, Sager HB, Courties G, Dutta P, Iwamoto Y, Zaltsman A, et al. Chronic variable stress activates hematopoietic stem cells. Nat Med. (2014) 20:754-8. doi: 10.1038/nm.3589

35. Eastell R, O'Neill TW, Hofbauer LC, Langdahl B, Reid IR, Gold DT, et al. Postmenopausal osteoporosis. Nat Rev Dis Primer. (2016) 2:16069. doi: 10.1038/nrdp.2016.69

36. Pietschmann P, Mechtcheriakova D, Meshcheryakova A, Föger-Samwald U, Ellinger I. Immunology of osteoporosis: a mini-review. Gerontology. (2016) 62:128-37. doi: 10.1159/000431091

37. Vega D, Maalouf NM, Sakhaee K. Clinical Review \#: the role of receptor activator of nuclear factor-kappaB (RANK)/RANK ligand/osteoprotegerin: clinical implications. J Clin Endocrinol Metab. (2007) 92:4514-21. doi: 10.1210/jc.2007-0646

38. Schildkraut JJ. The catecholamine hypothesis of affective disorders: a review of supporting evidence. Am J Psychiatry. (1965) 122:509-22. doi: 10.1176/ajp.122.5.509

39. Vaessen T, Hernaus D, Myin-Germeys I, van Amelsvoort T. The dopaminergic response to acute stress in health and psychopathology: a systematic review. Neurosci Biobehav Rev. (2015) 56:241-51. doi: 10.1016/j.neubiorev.2015.07.008

40. Rodrigues W, Madeira M, da Silva T, Clemente-Napimoga J, Miguel C, Diasda-Silva $\mathrm{V}$, et al. Low dose of propranolol down-modulates bone resorption by inhibiting inflammation and osteoclast differentiation. $\mathrm{Br} J$ Pharmacol. (2012) 165:2140-51. doi: 10.1111/j.1476-5381.2011.01686.x

41. Kondo H, Togari A. Continuous treatment with a low-dose $\beta$ agonist reduces bone mass by increasing bone resorption without suppressing bone formation. Calcif Tissue Int. (2011). 88:23-32. doi: $10.1007 / \mathrm{s} 00223-010-9421-9$

42. Kondo H, Takeuchi S, Togari A. $\beta$-Adrenergic signaling stimulates osteoclastogenesis via reactive oxygen species. Am J Physiol Endocrinol Metab. (2013) 304:E507-515. doi: 10.1152/ajpendo.00191.2012

43. Miller GE, Chen E, Sze J, Marin T, Arevalo JMG, Doll R, et al. A functional genomic fingerprint of chronic stress in humans: blunted glucocorticoid and increased NF-kappaB signaling. Biol Psychiatry. (2008) 64:266-72. doi: 10.1016/j.biopsych.2008.03.017

44. Chang MK, Raggatt L-J, Alexander KA, Kuliwaba JS, Fazzalari NL, Schroder K, et al. Osteal tissue macrophages are intercalated throughout human and mouse bone lining tissues and regulate osteoblast function in vitro and in vivo. J Immunol Baltim Md. (1950) (2008) 181:1232-44. doi: 10.4049/jimmunol.181.2.1232

45. Agha A, Monson JP. Modulation of glucocorticoid metabolism by the growth hormone - IGF-1 axis. Clin Endocrinol. (2007) 66:459-65. doi: $10.1111 / j .1365-2265.2007 .02763 . x$

46. Luo JM, Murphy LJ. Dexamethasone inhibits growth hormone induction of insulin-like growth factor-I (IGF-I) messenger ribonucleic acid (mRNA) in hypophysectomized rats and reduces IGF-I mRNA abundance in the intact rat. Endocrinology. (1989) 125:165-71. doi: 10.1210/endo-125-1-165

47. Zegarra-Valdivia JA. Insulin-like growth factor type 1 and its relation with neuropsychiatric disorders. Medwave. (2017) 17:e(7031) doi: 10.5867/medwave.2017.07.7031

48. Rosen CJ, Donahue LR, Hunter SJ. Insulin-like growth factors and bone: the osteoporosis connection. Proc Soc Exp Biol Med Soc Exp Biol Med NYN. (1994) 206:83-102. doi: 10.3181/00379727-206-43726

49. Bot M, Milaneschi Y, Penninx BWJH, Drent ML. Plasma insulin-like growth factor I levels are higher in depressive and anxiety disorders, but lower in antidepressant medication users. Psychoneuroendocrinology. (2016) 68:14855. doi: 10.1016/j.psyneuen.2016.02.028

50. Deuschle M, Blum WF, Strasburger CJ, Schweiger U, Weber B, Körner A, et al. Insulin-like growth factor-I (IGF-I) plasma concentrations are increased in depressed patients. Psychoneuroendocrinology. (1997) 22:493-503.

51. Santi A, Bot M, Aleman A, Penninx BWJH, Aleman IT. Circulating insulin-like growth factor I modulates mood and is a biomarker of vulnerability to stress: from mouse to man. Transl Psychiatry. (2018) 8:142. doi: 10.1038/s41398-018-0196-5 
52. Yu H, Watt H, Kesavan C, Mohan S. The negative impact of single prolonged stress (SPS) on bone development in mice. Stress Amst Neth. (2013) 16:56470. doi: 10.3109/10253890.2013.806908

53. Hoshaw BA, Hill TI, Crowley JJ, Malberg JE, Khawaja X, RosenzweigLipson S, et al. Antidepressant-like behavioral effects of IGF-I produced by enhanced serotonin transmission. Eur J Pharmacol. (2008) 594:109-16. doi: 10.1016/j.ejphar.2008.07.023

54. Canalis E. Growth factor control of bone mass. J Cell Biochem. (2009) 108:769-77. doi: 10.1002/jcb.22322

55. Xian L, Wu X, Pang L, Lou M, Rosen CJ, Qiu T, et al. Matrix IGF-1 maintains bone mass by activation of mTOR in mesenchymal stem cells. Nat Med. (2012) 18:1095-101. doi: 10.1038/nm.2793

56. Crane JL, Zhao L, Frye JS, Xian L, Qiu T, Cao X. IGF-1 Signaling is Essential for Differentiation of Mesenchymal Stem Cells for Peak Bone Mass. Bone Res. (2013) 1:186-94. doi: 10.4248/BR201302007

57. Einhorn TA, Buckwalter JA, O'Keefe RJ. Orthopaedic Basic Science: Foundations of Clinical Practice. Rosemont, IL: American Academy of Orthopaedic Surgeons. (2007) 490 p.

58. Bostrom MP, Saleh KJ, Einhorn TA. Osteoinductive growth factors in preclinical fracture and long bone defects models. Orthop Clin North Am. (1999) 30:647-58. doi: 10.1016/S0030-5898(05)70117-6

59. Sathyendra V, Darowish M. Basic science of bone healing. Hand Clin. (2013) 29:473-81. doi: 10.1016/j.hcl.2013.08.002

60. Perrini S, Laviola L, Carreira MC, Cignarelli A, Natalicchio A, Giorgino F. The GH/IGF1 axis and signaling pathways in the muscle and bone: mechanisms underlying age-related skeletal muscle wasting and osteoporosis. J Endocrinol. (2010) 205:201-10. doi: 10.1677/JOE-09-0431

61. Kang H, Sung J, Jung H-M, Woo KM, Hong S-D, Roh S. Insulin-like growth factor 2 promotes osteogenic cell differentiation in the parthenogenetic murine embryonic stem cells. Tissue Eng Part A. (2012) 18(3-4):331-41. doi: 10.1089/ten.tea.2011.0074

62. Minuto F, Palermo C, Arvigo M, Barreca AM. The IGF system and bone. $J$ Endocrinol Invest. (2005) 28(8 Suppl):8-10.

63. Riedemann J, Macaulay VM. IGF1R signalling and its inhibition. Endocr Relat Cancer. (2006) 13 Suppl 1:S33-43. doi: 10.1677/erc.1.01280

64. Burgdorf J, Colechio EM, Ghoreishi-Haack N, Gross AL, Rex CS, Zhang $\mathrm{X}$-L, et al. IGFBP2 Produces rapid-acting and long-lasting effects in rat models of posttraumatic stress disorder via a novel mechanism associated with structural plasticity. Int J Neuropsychopharmacol. (2017) 20:476-84. doi: 10.1093/ijnp/pyx007

65. Michel TM, Pülschen D, Thome J. The role of oxidative stress in depressive disorders. Curr Pharm Des. (2012) 18:5890-9. doi: 10.2174/138161212803523554

66. Mao W, Zhu Z. Parthenolide inhibits hydrogen peroxide-induced osteoblast apoptosis. Mol Med Rep. (2018) 17:8369-76. doi: 10.3892/mmr.2018.8908

67. Pan J-X, Tang F, Xiong F, Xiong L, Zeng P, Wang B, et al. APP promotes osteoblast survival and bone formation by regulating mitochondrial function and preventing oxidative stress. Cell Death Dis. (2018) 9:1077. doi: 10.1038/s41419-018-1123-7

68. Bartell SM, Kim H-N, Ambrogini E, Han L, Iyer S, Serra Ucer S, et al. FoxO proteins restrain osteoclastogenesis and bone resorption by attenuating $\mathrm{H} 2 \mathrm{O} 2$ accumulation. Nat Commun. (2014) 5:3773. doi: $10.1038 /$ ncomms 4773

69. Lee J, Son HS, Lee HI, Lee G-R, Jo Y-J, Hong S-E, et al. Skullcapflavone II inhibits osteoclastogenesis by regulating reactive oxygen species and attenuates the survival and resorption function of osteoclasts by modulating integrin signaling. FASEB J. (2018) 33 2026-2036. doi: 10.1096/fj.201800866RR

70. Song D, Cao Z, Liu Z, Tickner J, Qiu H, Wang C, et al. Cistanche deserticola polysaccharide attenuates osteoclastogenesis and bone resorption via inhibiting RANKL signaling and reactive oxygen species production. $J$ Cell Physiol. (2018) 233:9674-84. doi: 10.1002/jcp.26882

71. Almeida M, Han L, Martin-Millan M, Plotkin LI, Stewart SA, Roberson $\mathrm{PK}$, et al. Skeletal involution by age-associated oxidative stress and its acceleration by loss of sex steroids. J Biol Chem. (2007) 282:27285-97. doi: 10.1074/jbc.M702810200

72. Almeida M, Han L, Ambrogini E, Bartell SM, Manolagas SC. Oxidative stress stimulates apoptosis and activates NF-kappaB in osteoblastic cells via a PKCbeta/p66shc signaling cascade: counter regulation by estrogens or androgens. Mol Endocrinol Baltim Md. (2010) 24:2030-7. doi: 10.1210/me.2010-0189

73. Nazrun AS, Khairunnur A, Norliza M, Norazlina M, Ima Nirwana S. Effects of palm tocotrienols on oxidative stress and bone strength in ovariectomised rats. Med Health. (2008) 3:247-55.

74. Chin K-Y, Ima-Nirwana S. The biological effects of tocotrienol on bone: a review on evidence from rodent models. Drug Des Devel Ther. (2015) 9:2049-61. doi: 10.2147/DDDT.S79660

75. Sangkuhl K, Klein T, Altman R. Selective serotonin reuptake inhibitors pathway. Pharmacogenet Genomics. (2009) 19:907-9. doi: 10.1097/FPC.0b013e32833132cb

76. Wadhwa R, Kumar M, Talegaonkar S, Vohora D. Serotonin reuptake inhibitors and bone health: A review of clinical studies and plausible mechanisms. Osteoporos Sarcopenia. (2017) 3:75-81. doi: 10.1016/j.afos.2017.05.002

77. Dai SQ, Yu LP, Shi X, Wu H, Shao P, Yin GY, et al. Serotonin regulates osteoblast proliferation and function in vitro. Braz J Med Biol Res Rev Bras Pesqui Medicas E Biol. (2014) 47:759-65. doi: 10.1590/1414-431X20143565

78. Hirai T, Kaneshige K, Kurosaki T, Nishio H. Functional expression of 5-HT2A receptor in osteoblastic MC3T3-E1 cells. Biochem Biophys Res Commun. (2010) 396:278-82. doi: 10.1016/j.bbrc.2010.04.078

79. Hodge JM, Wang Y, Berk M, Collier FM, Fernandes TJ, Constable MJ, et al. Selective serotonin reuptake inhibitors inhibit human osteoclast and osteoblast formation and function. Biol Psychiatry. (2013) 74:32-9. doi: 10.1016/j.biopsych.2012.11.003

80. Battaglino R, Fu J, Späte U, Ersoy U, Joe M, Sedaghat L, et al. Serotonin regulates osteoclast differentiation through its transporter. J Bone Miner Res. (2004) 19:1420-31. doi: 10.1359/JBMR.040606

81. Ducy P, Karsenty G. The two faces of serotonin in bone biology. J Cell Biol. (2010) 191:7-13. doi: 10.1083/jcb.201006123

82. Dimitri P, Rosen C. The central nervous system and bone metabolism: an evolving story. Calcif Tissue Int. (2017) 100:476-85. doi: 10.1007/s00223-016-0179-6

83. Ko CH, Chan RLY, Siu WS, Shum WT, Leung PC, Zhang L, et al. Deteriorating effect on bone metabolism and microstructure by passive cigarette smoking through dual actions on osteoblast and osteoclast. Calcif Tissue Int. (2015) 96:389-400. doi: 10.1007/s00223-015-9 966-8

84. Cook BL, Wayne GF, Kafali EN, Liu Z, Shu C, Flores M. Trends in smoking among adults with mental illness and association between mental health treatment and smoking cessation. J Am Med Assoc. (2014) 311:172-82. doi: 10.1001/jama.2013.284985

85. Bijelic R, Milicevic S, Balaban J. Risk factors for osteoporosis in postmenopausal women. Med Arch. (2017) 71:25-8. doi: 10.5455/medarh.2017.71.25-28

86. Sampson HW. Alcohol, osteoporosis, and bone regulating hormones. Alcohol Clin Exp Res. (1997) 21:400-3. doi: 10.1111/j.1530-0277.1997.tb03782.x

87. Turner RT. Skeletal response to alcohol. Alcohol Clin Exp Res. (2000) 24:1693-701. doi: 10.1111/j.1530-0277.2000.tb01971.x

88. Chen X, Li M, Yan J, Liu T, Pan G, Yang H, et al. Alcohol induces cellular senescence and impairs osteogenic potential in bone marrowderived mesenchymal stem cells. Alcohol Alcohol Oxf Oxfs. (2017) 52:289-97. doi: 10.1093/alcalc/agx006

89. Davis MA, Lin LA, Liu H, Sites BD. Prescription opioid use among adults with mental health disorders in the United States. J Am Board Fam Med. (2017) 30:407-17. doi: 10.3122/jabfm.2017.04.170112

90. Ding Z, Chen Y, Wang X, zhou X, Xu Y, Ma Z, et al. A comparison of bone quality and its determinants in young opioid-dependent women with healthy control group. Drug Alcohol Depend. (2017) 175:232-6. doi: 10.1016/j.drugalcdep.2017.02.010

91. Walsh JS, Vilaca T. Obesity, Type 2 diabetes and bone in adults. Calcif Tissue Int. (2017) 100:528-35. doi: 10.1007/s00223-016-0229-0

92. Ensrud KE, Cauley J, Lipschutz R, Cummings SR. Weight change and fractures in older women. Study of Osteoporotic Fractures Research Group. Arch Intern Med. (1997) 157:857-63. doi: 10.1001/archinte.1997.00440290041004 
93. Cummings SR, Nevitt MC, Browner WS, Stone K, Fox KM, Ensrud $\mathrm{KE}$, et al. Risk factors for hip fracture in white women. Study of Osteoporotic Fractures Research Group. N Engl J Med. (1995) 332:767-73. doi: 10.1056/NEJM199503233321202

94. Crandall CJ, Yildiz VO, Wactawski-Wende J, Johnson KC, Chen Z, Going $\mathrm{SB}$, et al. Postmenopausal weight change and incidence of fracture: post hoc findings from Women's Health Initiative Observational Study and Clinical Trials. BMJ. (2015) 350:h25. doi: 10.1136/bmj.h25

95. Cauley JA, Thompson DE, Ensrud KC, Scott JC, Black D. Risk of mortality following clinical fractures. Osteoporos. (2000) 11:556-61. doi: $10.1007 / \mathrm{s} 001980070075$

96. Nguyen ND, Frost SA, Center JR, Eisman JA, Nguyen TV. Development of prognostic nomograms for individualizing 5-year and 10-year fracture risks. Osteoporos. (2008) 19:1431-44. doi: 10.1007/s00198-008-0588-0

97. Hippisley-Cox J, Coupland C. Predicting risk of osteoporotic fracture in men and women in England and Wales: prospective derivation and validation of QFractureScores. BMJ. (2009) 339:b doi: 10.1136/bmj.b4229

98. Bhattacharya R, Shen C, Sambamoorthi U. Excess risk of chronic physical conditions associated with depression and anxiety. BMC Psychiatry. (2014) 14:10. doi: 10.1186/1471-244X-14-10

99. Gold DT. The clinical impact of vertebral fractures: quality of life in women with osteoporosis. Bone. (1996) 18(3 Suppl):185S-189S. doi: 10.1016/8756-3282(95)00500-5

100. Crandall CJ, Newberry SJ, Diamant A, Lim Y-W, Gellad WF, Booth MJ, et al. Comparative effectiveness of pharmacologic treatments to prevent fractures: an updated systematic review. Ann Intern Med. (2014) 161:711-23. doi: $10.7326 / \mathrm{M} 14-0317$

101. Li C, Mori S, Li J, Kaji Y, Akiyama T, Kawanishi J, et al. Longterm effect of incadronate disodium (YM-175) on fracture healing of femoral shaft in growing rats. J Bone Miner Res. (2001) 16:429-36. doi: 10.1359/jbmr.2001.16.3.429

102. Black DM, Rosen CJ. Postmenopausal osteoporosis. N Engl J Med. (2016) 374:2096-7. doi: 10.1056/NEJMcp1513724

103. Citraro R, Gallelli L, Leo A, De PF, Gallelli P, Russo E, et al. Effects of chronic sodium alendronate on depression and anxiety in a menopausal experimental model. Pharmacol Biochem Behav. (2015) 129:6571. doi: 10.1016/j.pbb.2014.12.006

104. Eisenberg DF, Placzek H, Gu T, Krishna A, Tulsi BB. Cost and consequences of noncompliance to oral bisphosphonate treatment. J Manag Care Spec Pharm. (2015) 21:56-65. doi: 10.18553/jmcp.2015.21.1.56

105. Kronish IM, Edmondson D, Li Y, Cohen BE. Post-Traumatic Stress Disorder and Medication Adherence: Results from the Mind Your Heart Study. J Psychiatr Res. (2012) 46:1595-9. doi: 10.1016/j.jpsychires.2012.06.011

106. Kastelan D, Vlak T, Lozo P, Gradiser M, Mijic S, Nikolic T, et al. Healthrelated quality of life among patients with postmenopausal osteoporosis treated with weekly and monthly bisphosphonates. Endocr Res. (2010) 35:165-73. doi: 10.3109/07435800.2010.505218

107. Bone HG, Wagman RB, Brandi ML, Brown JP, Chapurlat R, Cummings $\mathrm{SR}$, et al. 10 years of denosumab treatment in postmenopausal women with osteoporosis: results from the phase 3 randomised FREEDOM trial and open-label extension. Lancet Diabetes Endocrinol. (2017) 5:513-23. doi: 10.1016/S2213-8587(17)30138-9

108. Cummings SR, Tice JA, Bauer S, Browner WS, Cuzick J, Ziv E, et al. Prevention of breast cancer in postmenopausal women: approaches to estimating and reducing risk. J Natl Cancer Inst. (2009) 101:384-98. doi: 10.1093/jnci/djp018

109. Anastasilakis AD, Polyzos SA, Makras P, Aubry-Rozier B, Kaouri S, Lamy O. Clinical features of 24 patients with rebound-associated vertebral fractures after denosumab discontinuation: systematic review and additional cases. J Bone Miner Res. (2017) 32:1291-6. doi: 10.1002/ jbmr.3110

110. Tsourdi E, Langdahl B, Cohen-Solal M, Aubry-Rozier B, Eriksen EF, Guañabens N, et al. Discontinuation of Denosumab therapy for osteoporosis: a systematic review and position statement by ECTS. Bone. (2017) 105:11-7. doi: 10.1016/j.bone.2017.08.003

111. Freemantle N, Satram-Hoang S, Tang E-T, Kaur P, Macarios D, Siddhanti $S$, et al. Final results of the DAPS (Denosumab Adherence Preference Satisfaction) study: a 24-month, randomized, crossover comparison with alendronate in postmenopausal women. Osteoporos. (2012) 23:317-26. doi: 10.1007/s00198-011-1780-1

112. Suzuki T, Nakamura Y, Kato H. Determination of serum bone-related minerals during denosumab treatment in osteoporosis patients with rheumatoid arthritis: Mineral change by denosumab in osteoporosis with rheumatoid arthritis. Clin Nutr ESPEN. (2018) 26:53-6. doi: 10.1016/j.clnesp.2018.04.014

113. Nagy V, Penninger JM. The RANKL-RANK Story. Gerontology. (2015) 61:534-42. doi: 10.1159/000371845

114. Kong YY, Feige U, Sarosi I, Bolon B, Tafuri A, Morony S, et al. Activated T cells regulate bone loss and joint destruction in adjuvant arthritis through osteoprotegerin ligand. Nature. (1999) 402:304-9. doi: 10.1038/35005552

115. Serrano EM, Ricofort RD, Zuo J, Ochotny N, Manolson MF, Holliday LS. Regulation of Vacuolar H+-ATPase in Microglia by RANKL. Biochem Biophys Res Commun. (2009) 389:193-7. doi: 10.1016/j.bbrc.2009.08.122

116. Guerrini MM, Okamoto K, Komatsu N, Sawa S, Danks L, Penninger JM, et al. Inhibition of the TNF family cytokine RANKL prevents autoimmune inflammation in the central nervous system. Immunity. (2015) 43:1174-85. doi: 10.1016/j.immuni.2015.10.017

117. Calcia MA, Bonsall DR, Bloomfield PS, Selvaraj S, Barichello T, Howes OD. Stress and neuroinflammation: a systematic review of the effects of stress on microglia and the implications for mental illness. Psychopharmacology. (2016) 233:1637-50. doi: 10.1007/s00213-016-4218-9

118. Elefteriou F, Ahn JD, Takeda S, Starbuck M, Yang X, Liu X, et al. Leptin regulation of bone resorption by the sympathetic nervous system and CART. Nature. (2005) 434:514-20. doi: 10.1038/nature03398

119. Takeda S, Elefteriou F, Levasseur R, Liu X, Zhao L, Parker KL, et al. Leptin regulates bone formation via the sympathetic nervous system. Cell. (2002) 111:305-17. doi: 10.1016/S0092-8674(02)01049-8

120. Wang J, Yu L, Jiang C, Fu X, Liu X, Wang M, et al. Cerebral ischemia increases bone marrow $\mathrm{CD} 4+\mathrm{CD} 25+\mathrm{FoxP} 3+$ regulatory $\mathrm{T}$ cells in mice via signals from sympathetic nervous system. Brain Behav Immun. (2015) 0:172-83. doi: 10.1016/j.bbi.2014.07.022

121. Gartlehner G, Patel SV, Feltner C, Weber RP, Long R, Mullican K, et al. Hormone therapy for the primary prevention of chronic conditions in postmenopausal women: evidence report and systematic review for the us preventive services task force. J Am Med Assoc. (2017) 318:2234-49. doi: 10.1001/jama.2017.16952

122. Lindsay R, Hart DM, Forrest C, Baird C. Prevention of spinal osteoporosis in oophorectomised women. Lancet Lond Engl. (1980) 2:1151-4. doi: 10.1016/S0140-6736(80)92592-1

123. Anderson GL, Limacher M, Assaf AR, Bassford T, Beresford SAA, Black H, et al. Effects of conjugated equine estrogen in postmenopausal women with hysterectomy: the Women's Health Initiative randomized controlled trial. J Am Med Assoc. (2004) 291:1701-12. doi: 10.1001/jama.291.14.1701

124. Ran SY, Yu Q, Chen Y, Lin SQ. Prevention of postmenopausal osteoporosis in Chinese women: a 5-year, double-blind, randomized, parallel placebocontrolled study. Climacteric J Int Menopause Soc. (2017) 20:391-6. doi: 10.1080/13697137.2017.1325459

125. Krantz E, Trimpou P, Landin-Wilhelmsen K. Effect of growth hormone treatment on fractures and quality of life in postmenopausal osteoporosis: a 10-year follow-up study. J Clin Endocrinol Metab. (2015) 100:3251-9. doi: 10.1210/jc.2015-1757

126. Kameda T, Mano H, Yuasa T, Mori Y, Miyazawa K, Shiokawa M, et al. Estrogen inhibits bone resorption by directly inducing apoptosis of the bone-resorbing osteoclasts. J Exp Med. (1997) 186:489-95. doi: 10.1084/jem.186.4.489

127. Brennan MÁ, Haugh MG, O’Brien FJ, McNamara LM. Estrogen withdrawal from osteoblasts and osteocytes causes increased mineralization and apoptosis. Horm Metab Res. (2014) 46:537-45. doi: 10.1055/s-0033-13 63265.

128. Pignolo R, Ahn J. Fractures in the Elderly: A Guide to Practical Management. 2nd ed. New York, NY: Humana Press (2018).

129. Weitzmann MN, Pacifici R. Estrogen regulation of immune cell bone interactions. Ann N Y Acad Sci. (2006) 1068:256-74. doi: 10.1196/annals.1346.030

130. Brincat SD, Borg M, Camilleri G, Calleja-Agius J. The role of cytokines in postmenopausal osteoporosis. Minerva Ginecol. (2014) 66:391-407. 
131. Tera T de M, Prado RF do, De Marco AC, Santamaria MP, Jardini MAN. The RANK/ RANKL/ OPG interaction in the repair of autogenous bone grafts in female rats with estrogen deficiency. Braz Oral Res. (2014) 28:1-9. doi: 10.1590/1807-3107BOR-2014.vol28.0054

132. Lindberg MK, Erlandsson M, Alatalo SL, Windahl S, Andersson G, Halleen $\mathrm{JM}$, et al. Estrogen receptor alpha, but not estrogen receptor beta, is involved in the regulation of the OPG/RANKL (osteoprotegerin/receptor activator of NF-kappa B ligand) ratio and serum interleukin-6 in male mice. J Endocrinol. (2001) 171:425-33. doi: 10.1677/joe.0.1710425

133. Bashir A, Mak YT, Sankaralingam S, Cheung J, McGowan NWA, Grigoriadis $\mathrm{AE}$, et al. Changes in RANKL/OPG/RANK gene expression in peripheral mononuclear cells following treatment with estrogen or raloxifene. Steroids. (2005) 70:847-55. doi: 10.1016/j.steroids.2005.04.011

134. Southmayd EA, De Souza MJ. A summary of the influence of exogenous estrogen administration across the lifespan on the GH/IGF-1 axis and implications for bone health. Growth Horm IGF Res. (2017) 32:2-13. doi: 10.1016/j.ghir.2016.09.001

135. Singhal V, Ackerman KE, Bose A, Torre Flores LP, Lee H, Misra M. Impact of route of estrogen administration on bone turnover markers in oligoamenorrheic athletes and its mediators. J Clin Endocrinol Metab. (2018) doi: 10.1210/jc.2018-02143

136. Hawse JR, Pitel KS, Cicek M, Philbrick KA, Gingery A, Peters KD, et al. TGF $\beta$ inducible early gene-1 plays an important role in mediating estrogen signaling in the skeleton. J Bone Miner Res. (2014) 29:1206-16. doi: $10.1002 /$ jbmr.2142

137. Jia J, Yao W, Amugongo S, Shahnazari M, Dai W, Lay Y-AE, et al. Prolonged alendronate treatment prevents the decline in serum TGF- $\beta 1$ levels and reduces cortical bone strength in long-term estrogen deficiency rat model. Bone. (2013) 52:424-32. doi: 10.1016/j.bone.2012.10.017

138. Chow J, Tobias JH, Colston KW, Chambers TJ. Estrogen maintains trabecular bone volume in rats not only by suppression of bone resorption but also by stimulation of bone formation. J Clin Invest. (1992) 89:74-8. doi: 10.1172/JCI115588

139. Rossouw JE, Anderson GL, Prentice RL, LaCroix AZ, Kooperberg C, Stefanick ML, et al. Risks and benefits of estrogen plus progestin in healthy postmenopausal women: principal results From the Women's Health Initiative randomized controlled trial. J Am Med Assoc. (2002) 288:321-33.

140. Qaseem A, Forciea MA, McLean RM, Denberg TD. Clinical guidelines committee of the american college of physicians. treatment of low bone density or osteoporosis to prevent fractures in men and women: a clinical practice guideline update from the American college of physicians. Ann Intern Med. (2017) 166:818-39. doi: 10.7326/M15-1361

141. Reid IR, Eastell R, Fogelman I, Adachi JD, Rosen A, Netelenbos C, et al. A comparison of the effects of raloxifene and conjugated equine estrogen on bone and lipids in healthy postmenopausal women. Arch Intern Med. (2004) 164:871-9. doi: 10.1001/archinte.164.8.871

142. Ettinger B, Black DM, Mitlak BH, Knickerbocker RK, Nickelsen T, Genant HK, et al. Reduction of vertebral fracture risk in postmenopausal women with osteoporosis treated with raloxifene: results from a 3-year randomized clinical trial. Multiple outcomes of raloxifene evaluation (MORE) investigators. J Am Med Assoc. (1999) 282:637-45. doi: 10.1001/jama.282.7.637

143. Vogel VG, Costantino JP, Wickerham DL, Cronin WM, Cecchini RS, Atkins JN, et al. Effects of tamoxifen vs raloxifene on the risk of developing invasive breast cancer and other disease outcomes: the NSABP Study of Tamoxifen and Raloxifene (STAR) P-2 trial. J Am Med Assoc. (2006) 295:2727-41. doi: 10.1001/jama.295.23.joc60074

144. Duvernoy CS, Yeo AA, Wong M, Cox DA, Kim HM. Antiplatelet therapy use and the risk of venous thromboembolic events in the raloxifene use for the heart (RUTH) trial. J Womens Health. (2010) 198:1459-65. doi: 10.1089/jwh.2009.1687

145. Gizzo S, Saccardi C, Patrelli TS, Berretta R, Capobianco G, Di Gangi $S$, et al. Update on raloxifene: mechanism of action, clinical efficacy, adverse effects, and contraindications. Obstet Gynecol Surv. (2013) 68:46781. doi: 10.1097/OGX.0b013e31828baef9

146. Barrett-Connor E, Cauley JA, Kulkarni PM, Sashegyi A, Cox DA, Geiger MJ. Risk-benefit profile for raloxifene: 4-year data From the Multiple Outcomes of Raloxifene Evaluation (MORE) randomized trial. J Bone Miner Res. (2004) 19:1270-5. doi: 10.1359/JBMR.040406

147. Ceresini G, Freddi M, Morganti S, Rebecchi I, Modena AB, Rinaldi M, et al. The effects of transdermal estradiol on the response to mental stress in postmenopausal women: a randomized trial. Am J Med. (2000) 109:463-8. doi: 10.1016/S0002-9343(00)00523-4

148. Puder JJ, Freda PU, Goland RS, Wardlaw SL. Estrogen modulates the hypothalamic-pituitary-adrenal and inflammatory cytokine responses to endotoxin in women. J Clin Endocrinol Metab. (2001) 86:2403-8. doi: 10.1210/jc.86.6.2403

149. Ycaza Herrera A, Mather M. Actions and interactions of estradiol and glucocorticoids in cognition and the brain: Implications for aging women. Neurosci Biobehav Rev. (2015) 55:36-52. doi: 10.1016/j.neubiorev.2015.04.005

150. Herrera AY, Hodis HN, Mack WJ, Mather M. Estradiol therapy after menopause mitigates effects of stress on cortisol and working memory. J Clin Endocrinol Metab. (2017) 102:4457-66. doi: 10.1210/jc.2017-00825

151. Rubinow DR, Schmidt PJ, Roca CA. Estrogen-serotonin interactions: implications for affective regulation. Biol Psychiatry. (1998) 44:839-50. doi: 10.1016/S0006-3223(98)00162-0

152. Borrow AP, Handa RJ. Estrogen receptors modulation of anxiety-like behavior. Vitam Horm. (2017) 103:27-52. doi: 10.1016/bs.vh.2016.08.004

153. Glover EM, Jovanovic T, Mercer KB, Kerley K, Bradley B, Ressler KJ, et al. Estrogen levels are associated with extinction deficits in women with posttraumatic stress disorder. Biol Psychiatry. (2012) 72:19-24. doi: 10.1016/j.biopsych.2012.02.031

154. Shansky RM, Bender G, Arnsten AFT. Estrogen prevents norepinephrine alpha-2a receptor reversal of stress-induced working memory impairment. Stress Amst Neth. (2009) 12:457-63. doi: 10.1080/10253890802520988

155. Cheung J, Chervonsky L, Felmingham KL, Bryant RA. The role of estrogen in intrusive memories. Neurobiol Learn Mem. (2013) 106:87-94. doi: 10.1016/j.nlm.2013.07.005

156. Peterlin BL, Katsnelson MJ, Calhoun AH. The associations between migraine, unipolar psychiatric comorbidities, and stress-related disorders and the role of estrogen. Curr Pain Headache Rep. (2009) 13:404-12. doi: 10.1007/s11916-009-0066-1

157. Ruan F, Zheng Q, Wang J. Mechanisms of bone anabolism regulated by statins. Biosci Rep. (2012) 32:511-9. doi: 10.1042/BSR20110118

158. Mundy G, Garrett R, Harris S, Chan J, Chen D, Rossini G, et al. Stimulation of bone formation in vitro and in rodents by statins. Science. (1999) 286:1946-9. doi: 10.1126/science.286.5446.1946

159. Wang Z, Li Y, Zhou F, Piao Z, Hao J. Effects of statins on bone mineral density and fracture risk. Medicine. (2016) 95:e3042. doi: 10.1097/MD.0000000000003042

160. Jadhav SB, Narayana Murthy PS, Singh MM, Jain GK. Distribution of lovastatin to bone and its effect on bone turnover in rats. J Pharm Pharmacol. (2006) 58:1451-8. doi: 10.1211/jpp.58.11.0005

161. Koida M, Fukuyama R, Nakamuta H. Osteoporosis requires bone-specific statins. Curr Pharm Des. (2004) 10:2605-13. doi: 10.2174/1381612043383827

162. Lin P-Y, Chang AYW, Lin T-K. Simvastatin treatment exerts antidepressantlike effect in rats exposed to chronic mild stress. Pharmacol Biochem Behav. (2014) 124:174-9. doi: 10.1016/j.pbb.2014.06.006

163. Singh D, Lippmann S. Can statins diminish depression? Prim Care Companion CNS Disord. (2018) 20. doi: 10.4088/PCC.17br 02169

164. Cham S, Koslik HJ, Golomb BA. Mood, personality, and behavior changes during treatment with statins: a case series. Drug Saf Case Rep. (2015) 3:1. doi: 10.1007/s40800-015-0024-2

165. Salagre E, Fernandes BS, Dodd S, Brownstein DJ, Berk M. Statins for the treatment of depression: A meta-analysis of randomized, doubleblind, placebo-controlled trials. J Affect Disord. (2016) 200:235-42. doi: 10.1016/j.jad.2016.04.047

166. Bedi O, Dhawan V, Sharma PL, Kumar P. Pleiotropic effects of statins: new therapeutic targets in drug design. Naunyn Schmiedebergs Arch Pharmacol. (2016) 389:695-712. doi: 10.1007/s00210-016-1252-4

167. Meunier PJ, Roux C, Ortolani S, Diaz-Curiel M, Compston J, Marquis P, et al. Effects of long-term strontium ranelate treatment on vertebral fracture risk 
in postmenopausal women with osteoporosis. Osteoporos. (2009) 20:166373. doi: 10.1007/s00198-008-0825-6

168. Reginster JY, Seeman E, De Vernejoul MC, Adami S, Compston J, Phenekos C, et al. Strontium ranelate reduces the risk of nonvertebral fractures in postmenopausal women with osteoporosis: Treatment of Peripheral Osteoporosis (TROPOS) study. J Clin Endocrinol Metab. (2005) 90:2816-22. doi: $10.1210 /$ jc. $2004-1774$

169. Cooper C, Fox KM, Borer JS. Ischaemic cardiac events and use of strontium ranelate in postmenopausal osteoporosis: a nested case-control study in the CPRD. Osteoporos. (2014) 25:737-45. doi: 10.1007/s00198-013-2582-4

170. Marquis P, Roux C, de la Loge C, Diaz-Curiel M, Cormier C, Isaia G, et al. Strontium ranelate prevents quality of life impairment in post-menopausal women with established vertebral osteoporosis. Osteoporos. (2008) 19:50310. doi: $10.1007 /$ s00198-007-0464-3

171. Rozhinskaia LI, Arapova SD, Dzeranova LK, Molitvoslovova NN, Marova $\mathrm{EI}$, Il'in AV, et al. Efficacy and safety of bivalos therapy for postmenopausal osteoporosis. Results of Russian multicenter trial. Ter Arkh. (2008) 80:47-52.

172. Gambacciani M, Levancini M. Management of postmenopausal osteoporosis and the prevention of fractures. Panminerva Med. (2014) 56:115-31. doi: 10.1146/annurev-med-070313-022841

173. McClung MR, San Martin J, Miller PD, Civitelli R, Bandeira F, Omizo M, et al. Opposite bone remodeling effects of teriparatide and alendronate in increasing bone mass. Arch Intern Med. (2005) 165:1762-8. doi: $10.1001 /$ archinte.165.15.1762

174. Neer RM, Arnaud CD, Zanchetta JR, Prince R, Gaich GA, Reginster JY, et al. Effect of parathyroid hormone (1-34) on fractures and bone mineral density in postmenopausal women with osteoporosis. N Engl J Med. (2001) 344:1434-41. doi: 10.1056/NEJM200105103441904

175. Black DM, Greenspan SL, Ensrud KE, Palermo L, McGowan JA, Lang TF, et al. The Effects of parathyroid hormone and alendronate alone or in combination in postmenopausal osteoporosis. N Engl J Med. (2003) 349:1207-15. doi: 10.1056/NEJMoa031975

176. Terzioglu-Usak S, Elibol B, Dalli T, Guler C, Aysan E. Effect of restraint stress on plasma PTH concentration and its molecular targets expressions in wistar rats. Int J Endocrinol Metab. (2018) 16:e66979. doi: 10.5812/ijem.66979

177. Lasco A, Catalano A, Morabito N, Gaudio A, Basile G, Trifiletti A, et al. Adrenal effects of teriparatide in the treatment of severe postmenopausal osteoporosis. Osteoporos. (2011) 22:299-303. doi: $10.1007 / \mathrm{s} 00198-010-1222-5$

178. Dorn LD, Susman EJ, Pabst S, Huang B, Kalkwarf H, Grimes S. Association of depressive symptoms and anxiety with bone mass and density in eversmoking and never-smoking adolescent girls. Arch Pediatr Adolesc Med. (2008) 162:1181-8. doi: 10.1001/archpedi.162.12.1181

179. Tolea MI, Black SA, Carter-Pokras OD, Kling MA. Depressive symptoms as a risk factor for osteoporosis and fractures in older Mexican American women. Osteoporos. (2007) 18:315-22. doi: 10.1007/s00198-006-0242-7

180. Cizza G, Primma S, Coyle M, Gourgiotis L, Csako G. Depression and osteoporosis: a research synthesis with meta-analysis. Horm Metab Res. (2010) 42:467-82. doi: 10.1055/s-0030-1252020

181. Mussolino ME. Depression and hip fracture risk: the NHANES I epidemiologic follow-up study. Public Health Rep Wash DC. (2005) 120:715. doi: $10.1177 / 003335490512000112$

182. Martin RM, Hilton SR, Kerry SM, Richards NM. General practitioners' perceptions of the tolerability of antidepressant drugs: a comparison of selective serotonin reuptake inhibitors and tricyclic antidepressants. BMJ. (1997) 314:646-51.

183. Bolo NR, Hodé Y, Macher J-P. Long-term sequestration of fluorinated compounds in tissues after fluvoxamine or fluoxetine treatment: a fluorine magnetic resonance spectroscopy study in vivo. Magn Reson Mater Phys Biol Med. (2004) 16:268-76. doi: 10.1007/s10334-004-0033-0

184. Ortuño MJ, Robinson ST, Subramanyam P, Paone R, Huang Y-Y, Guo XE, et al. Serotonin-reuptake inhibitors act centrally to cause bone loss in mice by counteracting a local anti-resorptive effect. Nat Med. (2016) 22:1170-9. doi: $10.1038 / \mathrm{nm} .4166$.

185. Rauma PH, Pasco JA, Berk M, Stuart AL, Koivumaa-Honkanen H, Honkanen RJ, et al. The association between major depressive disorder, use of antidepressants and bone mineral density (BMD) in men. J Musculoskelet Neuronal Interact. (2015) 15:177-85.
186. Rabenda V, Nicolet D, Beaudart C, Bruyère O, Reginster J-Y. Relationship between use of antidepressants and risk of fractures: a meta-analysis. Osteoporos. (2013) 24:121-37. doi: 10.1007/s00198-012-2015-9

187. Vestergaard P, Rejnmark L, Mosekilde L. Anxiolytics, sedatives, antidepressants, neuroleptics and the risk of fracture. Osteoporos. (2006) 17:807-16. doi: 10.1007/s00198-005-0065-y

188. Vestergaard P, Rejnmark L, Mosekilde L. Selective serotonin reuptake inhibitors and other antidepressants and risk of fracture. Calcif Tissue Int. (2008) 82:92-101. doi: 10.1007/s00223-007-9099-9

189. Liu B, Anderson G, Mittmann N, To T, Axcell T, Shear N. Use of selective serotonin-reuptake inhibitors or tricyclic antidepressants and risk of hip fractures in elderly people. Lancet Lond Engl. (1998) 351:1303-7. doi: 10.1016/S0140-6736(97)09528-7

190. Haney EM, Chan BKS, Diem SJ, Ensrud KE, Cauley JA, Barrett-Connor E, et al. Association of low bone mineral density with selective serotonin reuptake inhibitor use by older men. Arch Intern Med. (2007) 167:1246-51. doi: 10.1001/archinte.167.12.1246

191. Chau K, Atkinson SA, Taylor VH. Are selective serotonin reuptake inhibitors a secondary cause of low bone density? J Osteoporos. (2012) 2012:32. doi: 10.1155/2012/323061

192. Seifert CF, Wiltrout TR. Calcaneal bone mineral density in young adults prescribed selective serotonin reuptake inhibitors. Clin Ther. (2013) 35:1412-7. doi: 10.1016/j.clinthera.2013.07.423

193. Brown PM, Drossman DA, Wood AJJ, Cline GA, Frazier KS, Jackson JI, et al. The tryptophan hydroxylase inhibitor LX1031 shows clinical benefit in patients with nonconstipating irritable bowel syndrome. Gastroenterology. (2011) 141:507-16. doi: 10.1053/j.gastro.2011.05.005

194. Yadav VK, Balaji S, Suresh PS, Liu XS, Lu X, Li Z, et al. Inhibition of gutderived serotonin synthesis: a potential bone anabolic treatment. Nat Med. (2010) 16:308-12. doi: 10.1038/nm.2098

195. Inose H, Zhou B, Yadav VK, Guo XE, Karsenty G, Ducy P. Efficacy of serotonin inhibition in mouse models of bone loss. J Bone Miner Res. (2011) 26:2002-11. doi: 10.1002/jbmr.439

196. Haney EM, Warden SJ, Bliziotes MM. Effects of selective serotonin reuptake inhibitors on bone health in adults: time for recommendations about screening, prevention and management? Bone. (2010) 46:13-7. doi: 10.1016/j.bone.2009.07.083

197. Xing D, Ma XL, Ma JX, Wang J, Yang Y, Chen Y. Association between use of benzodiazepines and risk of fractures: a meta-analysis. Osteoporos. (2014) 25:105-20. doi: 10.1007/s00198-013-2446-y

198. Fan H-C, Lee H-S, Chang K-P, Lee Y-Y, Lai H-C, Hung P-L, et al. The Impact of Anti-Epileptic Drugs on Growth and Bone Metabolism. Int J Mol Sci. (2016) 17. doi: 10.3390/ijms 17081242

199. Rice JN, Gillett CB, Malas NM. The Impact of psychotropic medications on bone health in youth. Curr Psychiatry Rep. (2018) 20:104. doi: $10.1007 /$ s11920-018-0960-5

200. Fitzpatrick LA. Pathophysiology of bone loss in patients receiving anticonvulsant therapy. Epilepsy Behav EB. (2004) 5 Suppl 2:S3-15. doi: 10.1016/j.yebeh.2003.11.026

201. Soltani D, Ghaffar pour M, Tafakhori A, Sarraf P, Bitarafan S. Nutritional aspects of treatment in epileptic patients. Iran J Child Neurol. (2016) 10:1-12.

202. Weinstein RS, Bryce GF, Sappington LJ, King DW, Gallagher BB. Decreased serum ionized calcium and normal vitamin D metabolite levels with anticonvulsant drug treatment. J Clin Endocrinol Metab. (1984) 58:1003-9. doi: $10.1210 /$ jcem-58-6-1003

203. Roque AP. Pharmacotherapy as prophylactic treatment of post-traumatic stress disorder: a review of the literature. Issues Ment Health Nurs. (2015) 36:740-51. doi: 10.3109/01612840.2015.1057785

204. Burbiel JC. Primary prevention of posttraumatic stress disorder: drugs and implications. Mil Med Res. (2015) 2:24 doi: 10.1186/s40779-01 5-0053-2

205. Bonnet N, Gadois C, McCloskey E, Lemineur G, Lespessailles E, Courteix $D$, et al. Protective effect of beta blockers in postmenopausal women: influence on fractures, bone density, micro and macroarchitecture. Bone. (2007) 40:1209-16. doi: 10.1016/j.bone.2007.01.006

206. Ağaçayak KS, Güven S, Koparal M, Güneş N, Atalay Y, Atilgan S. Long-term effects of antihypertensive medications on bone mineral density in men older than 55 years. Clin Interv Aging. (2014) 9:509-13. doi: 10.2147/CIA.S60669 
207. Schlienger RG, Kraenzlin ME, Jick SS, Meier CR. Use of betablockers and risk of fractures. J Am Med Assoc. (2004) 292:1326-32. doi: 10.1001/jama.292.11.1326

208. Pasco JA, Henry MJ, Sanders KM, Kotowicz MA, Seeman E, Nicholson GC, et al. Beta-adrenergic blockers reduce the risk of fracture partly by increasing bone mineral density: Geelong Osteoporosis Study. J Bone Miner Res. (2004) 19:19-24. doi: 10.1359/jbmr.0301214

209. Sadr K, Aghbali A, Sadr M, Abachizadeh H, Azizi M, Mesgari Abbasi M. Effect of beta-blockers on number of osteoblasts and osteoclasts in alveolar socket following tooth extraction in wistar rats. J Dent. (2017) 18:37-42.

210. Daly RM, Duckham RL, Gianoudis J. Evidence for an interaction between exercise and nutrition for improving bone and muscle health. Curr Osteoporos Rep. (2014) 12:219-26. doi: 10.1007/s11914-014-0207-2

211. Sarris J, O’Neil A, Coulson CE, Schweitzer I, Berk M. Lifestyle medicine for depression. BMC Psychiatry. (2014) 14:107. doi: 10.1186/1471-244X-14-107

212. Romero Pérez A, Rivas Velasco A. Adherence to Mediterranean diet and bone health. Nutr Hosp. (2014) 29:989-96. doi: 10.3305/nh.2014.29.5.7332

213. Parletta N, Zarnowiecki D, Cho J, Wilson A, Bogomolova S, Villani A, et al. A Mediterranean-style dietary intervention supplemented with fish oil improves diet quality and mental health in people with depression: a randomized controlled trial (HELFIMED). Nutr Neurosci. (2017) 1-14. doi: 10.1080/1028415X.2017.1411320

214. Ilich JZ, Kelly OJ, Kim Y, Spicer MT. Low-grade chronic inflammation perpetuated by modern diet as a promoter of obesity and osteoporosis. Arh Hig Rada Toksikol. (2014) 65:139-48. doi: 10.2478/10004-1254-65-2014-2541

215. Hinton PS, Nigh P, Thyfault J. Effectiveness of resistance training or jumping-exercise to increase bone mineral density in men with low bone mass: A 12-month randomized, clinical trial. Bone. (2015) 79:203-12. doi: 10.1016/j.bone.2015.06.008

216. Howe TE, Shea B, Dawson LJ, Downie F, Murray A, Ross $\mathrm{C}$, et al. Exercise for preventing and treating osteoporosis in postmenopausal women. Cochrane Database Syst Rev. (2011) 2011:CD00. doi: 10.1002/14651858.CD000333.pub2

217. Kemmler W, Bebenek M, Kohl M, von Stengel S. Exercise and fractures in postmenopausal women. Final results of the controlled erlangen fitness and osteoporosis prevention study (EFOPS). Osteoporos. (2015) 26:2491-9. doi: 10.1007/s00198-015-3165-3

218. Evans RK, Negus CH, Centi AJ, Spiering BA, Kraemer WJ, Nindl BC. Peripheral QCT sector analysis reveals early exercise-induced increases in tibial bone mineral density. J Musculoskelet Neuronal Interact. (2012) 12:155-64.

219. Snow-Harter C, Whalen R, Myburgh K, Arnaud S, Marcus R. Bone mineral density, muscle strength, and recreational exercise in men. J Bone Miner Res. (1992) 7:1291-6. doi: 10.1002/jbmr.5650071108

220. Michaëlsson K, Olofsson H, Jensevik K, Larsson S, Mallmin H, Berglund L, et al. Leisure physical activity and the risk of fracture in men. PLoS Med. (2007) 4:e199. doi: 10.1371/journal.pmed.0040199

221. Fetzner MG, Asmundson GJG. Aerobic exercise reduces symptoms of posttraumatic stress disorder: a randomized controlled trial. Cogn Behav Ther. (2015) 44:301-13. doi: 10.1080/16506073.2014.916745

222. Jayakody K, Gunadasa S, Hosker C. Exercise for anxiety disorders: systematic review. Br J Sports Med. (2014) 48:187-96. doi: 10.1136/bjsports-2012-091287

223. Strickland JC, Smith MA. The anxiolytic effects of resistance exercise. Front Psychol. (2014) 5:753. doi: 10.3389/fpsyg.2014.00753

224. Ströhle A, Feller C, Onken M, Godemann F, Heinz A, Dimeo F. The acute antipanic activity of aerobic exercise. Am J Psychiatry. (2005) 162:2376-8. doi: 10.1176/appi.ajp.162.12.2376

225. Wipfli BM, Rethorst CD, Landers DM. The anxiolytic effects of exercise: a meta-analysis of randomized trials and dose-response analysis. J Sport Exerc Psychol. (2008) 30:392-410. doi: 10.1123/jsep.30.4.392

226. Rosenbaum S, Sherrington C, Tiedemann A. Exercise augmentation compared with usual care for post-traumatic stress disorder: a randomized controlled trial. Acta Psychiatr Scand. (2015) 131:350-9. doi: 10.1111 /acps. 12371

227. Mirescu C, Gould E. Stress and adult neurogenesis. Hippocampus. (2006) 16:233-8. doi: 10.1002/hipo.20155
228. Lagace DC, Donovan MH, DeCarolis NA, Farnbauch LA, Malhotra S, Berton $\mathrm{O}$, et al. Adult hippocampal neurogenesis is functionally important for stressinduced social avoidance. Proc Natl Acad Sci USA. (2010) 107:4436-41. doi: 10.1073/pnas.0910072107

229. Heine VM, Maslam S, Zareno J, Joëls M, Lucassen PJ. Suppressed proliferation and apoptotic changes in the rat dentate gyrus after acute and chronic stress are reversible. Eur J Neurosci. (2004) 19:131-44. doi: 10.1046/j.1460-9568.2003.03100.x

230. Schoenfeld TJ, Gould E. Stress, stress hormones, and adult neurogenesis. Exp Neurol. (2012) 233:12-21. doi: 10.1016/j.expneurol.2011.01.008

231. van Praag $H$. Neurogenesis and exercise: past and future directions. Neuromolecular Med. (2008) 10:128-40. doi: 10.1007/s12017-008-8028-z

232. Rhodes JS, van Praag H, Jeffrey S, Girard I, Mitchell GS, Garland T, et al. Exercise increases hippocampal neurogenesis to high levels but does not improve spatial learning in mice bred for increased voluntary wheel running. Behav Neurosci. (2003) 117:1006-16. doi: 10.1037/0735-7044.117.5.1006

233. E Dief A, M Samy D, I Dowedar F. Impact of exercise and vitamin B1 intake on hippocampal brain-derived neurotrophic factor and spatial memory performance in a rat model of stress. J Nutr Sci Vitaminol. (2015) 61:1-7. doi: $10.3177 /$ jnsv.61.1

234. Lou S, Liu J, Chang H, Chen P. Hippocampal neurogenesis and gene expression depend on exercise intensity in juvenile rats. Brain Res. (2008) 1210:48-55. doi: 10.1016/j.brainres.2008.02.080

235. de Almeida AA, Gomes da Silva S, Fernandes J, Peixinho-Pena LF, Scorza FA, Cavalheiro EA, et al. Differential effects of exercise intensities in hippocampal BDNF, inflammatory cytokines and cell proliferation in rats during the postnatal brain development. Neurosci Lett. (2013) 553:1-6. doi: 10.1016/j.neulet.2013.08.015

236. Gomes da Silva S, Unsain N, Mascó DH, Toscano-Silva M, de Amorim $\mathrm{HA}$, Silva Araújo BH, et al. Early exercise promotes positive hippocampal plasticity and improves spatial memory in the adult life of rats. Hippocampus. (2012) 22:347-58. doi: 10.1002/hipo.20903

237. Droste SK, Gesing A, Ulbricht S, Müller MB, Linthorst ACE, Reul JMHM. Effects of long-term voluntary exercise on the mouse hypothalamicpituitary-adrenocortical axis. Endocrinology. (2003) 144:3012-23. doi: 10.1210/en.2003-0097

238. Droste SK, Chandramohan Y, Hill LE, Linthorst ACE, Reul JMHM. Voluntary exercise impacts on the rat hypothalamic-pituitary-adrenocortical axis mainly at the adrenal level. Neuroendocrinology. (2007) 86:26-37. doi: $10.1159 / 000104770$

239. Radecki DT, Brown LM, Martinez J, Teyler TJ. BDNF protects against stress-induced impairments in spatial learning and memory and LTP. Hippocampus. (2005) 15:246-53. doi: 10.1002/hipo.20048

240. Sabourin BC, Stewart SH, Watt MC, Krigolson OE. Running as interoceptive exposure for decreasing anxiety sensitivity: replication and extension. Cogn Behav Ther. (2015) 44:264-74. doi: 10.1080/16506073.2015.1015163

241. Watt MC, Stewart SH, Lefaivre M-J, Uman LS. A brief cognitivebehavioral approach to reducing anxiety sensitivity decreases pain-related anxiety. Cogn Behav Ther. (2006) 35:248-56. doi: 10.1080/165060706008 98553

242. Arntz A. Cognitive therapy versus interoceptive exposure as treatment of panic disorder without agoraphobia. Behav Res Ther. (2002) 40:325-41. doi: 10.1016/S0005-7967(01)00014-6

243. Wald J, Taylor S. Responses to interoceptive exposure in people with posttraumatic stress disorder (PTSD): a preliminary analysis of induced anxiety reactions and trauma memories and their relationship to anxiety sensitivity and PTSD symptom severity. Cogn Behav Ther. (2008) 37:90-100. doi: 10.1080/16506070801969054

244. Salmon P. Effects of physical exercise on anxiety, depression, and sensitivity to stress: a unifying theory. Clin Psychol Rev. (2001) 21:33-61. doi: 10.1016/S0272-7358(99)00032-X

245. Ströhle A. Physical activity, exercise, depression and anxiety disorders. J Neural Transm Vienna Austria. (2009) 116:777-84. doi: 10.1007/s00702-008-0092-x.

246. Bossini L, Tavanti M, Calossi S, Lombardelli A, Polizzotto NR, Galli R, et al. Magnetic resonance imaging volumes of the hippocampus in drug-naïve patients with post-traumatic stress disorder without comorbidity conditions. J Psychiatr Res. (2008) 42:752-62. doi: 10.1016/j.jpsychires.2007.08.004 
247. Jackson RD, LaCroix AZ, Gass M, Wallace RB, Robbins J, Lewis CE, et al. Calcium plus vitamin D supplementation and the risk of fractures. $N$ Engl J Med. (2006) 354:669-83. doi: 10.1056/NEJMoa055218

248. Weaver CM, Alexander DD, Boushey CJ, Dawson-Hughes B, Lappe JM, LeBoff MS, et al. Calcium plus vitamin D supplementation and risk of fractures: an updated meta-analysis from the National Osteoporosis Foundation. Osteoporos. (2016) 27:367-76. doi: 10.1007/s00198-015-3386-5

249. LeBlanc ES, Zakher B, Daeges M, Pappas M, Chou R. Screening for vitamin D deficiency: a systematic review for the U.S. preventive services task force. Ann Intern Med. (2015) 162:109-22. doi: 10.7326/M14-1659

250. Shaffer JA, Edmondson D, Wasson LT, Falzon L, Homma K, Ezeokoli N, et al. Vitamin D supplementation for depressive symptoms: A systematic review and meta-analysis of randomized controlled trials. Psychosom Med. (2014) 76:190-6. doi: 10.1097/PSY.0000000000000044

251. Bertone-Johnson ER. Vitamin D and the occurrence of depression: causal association or circumstantial evidence? Nutr Rev. (2009) 67:481-92. doi: 10.1111/j.1753-4887.2009.00220.x

252. McCann JC, Ames BN. Is there convincing biological or behavioral evidence linking vitamin D deficiency to brain dysfunction? FASEB J. (2008) 22:9821001. doi: 10.1096/fj.07-9326rev

253. Eyles DW, Smith S, Kinobe R, Hewison M, McGrath JJ. Distribution of the vitamin D receptor and 1 alpha-hydroxylase in human brain. J Chem Neuroanat. (2005) 29:21-30. doi: 10.1016/j.jchemneu.2004.08.006

254. Martino G, Catalano A, Bellone F, Sardella A, Lasco C, Caprì T, et al. Vitamin D status is associated with anxiety levels in postmenopausal women evaluated for osteoporosis. Mediterr J Clin Psychol. (2018) 6:1-16. doi: 10.6092/2282-1619/2018.6.1740

255. Catalano A, Martino G, Bellone F, Gaudio A, Lasco C, Langher V, et al. Anxiety levels predict fracture risk in postmenopausal women assessed for osteoporosis. Menopause N Y N. (2018) 25:1110-5. doi: 10.1097/GME.0000000000001123

256. Martino G, Catalano A, Bellone F, Langher V, Lasco C, Penna A, et al. Quality of life in postmenopausal women: which role for vitamin D? Mediterr J Clin Psychol. (2018) 6. doi: 10.6092/2282-1619/2018.6.1875

257. Baksi SN, Hughes MJ. Chronic vitamin D deficiency in the weanling rat alters catecholamine metabolism in the cortex. Brain Res. (1982) 242:387-90. doi: 10.1016/0006-8993(82)90331-6

258. Bertone-Johnson ER, Powers SI, Spangler L, Larson J, Michael YL, Millen AE, et al. Vitamin D supplementation and depression in the women's health initiative calcium and Vitamin D Trial. Am J Epidemiol. (2012) 176:1-13. doi: 10.1093/aje/kwr482

259. Jorde R, Sneve M, Figenschau Y, Svartberg J, Waterloo K. Effects of vitamin $\mathrm{D}$ supplementation on symptoms of depression in overweight and obese subjects: randomized double blind trial. J Intern Med. (2008) 264:599-609. doi: 10.1111/j.1365-2796.2008.02008.x

260. Bae Y-J, Kim S-K. Low dietary calcium is associated with self-rated depression in middle-aged Korean women. Nutr Res Pract. (2012) 6:527-33. doi: 10.4162/nrp.2012.6.6.527

261. Ghanbari Z, Haghollahi F, Shariat M, Foroshani AR, Ashrafi M. Effects of calcium supplement therapy in women with premenstrual syndrome. Taiwan J Obstet Gynecol. (2009) 48:124-9. doi: 10.1016/S1028-4559(09) 60271-0

262. Dennis C-LE. Preventing postpartum depression part I: a review of biological interventions. Can J Psychiatry. (2004) 49:467-75. doi: 10.1177/070674370404900708

263. Al Alawi AM, Majoni SW, Falhammar H. Magnesium and Human Health: Perspectives and Research Directions. Int J Endocrinol. (2018) 2018:9041694 doi: 10.1155/2018/9041694

264. Razzaque MS. Magnesium: are we consuming enough? Nutrients. (2018) 10. doi: 10.3390/nu10121863

265. Alfrey AC, Miller NL. Bone magnesium pools in uremia. J Clin Invest. (1973) 52:3019-27. doi: 10.1172/JCI107500

266. Rude RK, Gruber HE, Norton HJ, Wei LY, Frausto A, Kilburn J. Dietary magnesium reduction to $25 \%$ of nutrient requirement disrupts bone and mineral metabolism in the rat. Bone. (2005) 37:211-9. doi: 10.1016/j.bone.2005.04.005

267. Tucker KL, Hannan MT, Chen H, Cupples LA, Wilson PW, Kiel DP. Potassium, magnesium, and fruit and vegetable intakes are associated with greater bone mineral density in elderly men and women. Am J Clin Nutr. (1999) 69:727-36. doi: 10.1093/ajcn/69.4.727
268. Orchard TS, Larson JC, Alghothani N, Bout-Tabaku S, Cauley JA, Chen Z, et al. Magnesium intake, bone mineral density, and fractures: results from the women's health initiative observational study. Am J Clin Nutr. (2014) 99:926-33. doi: 10.3945/ajcn.113.067488

269. Veronese N, Stubbs B, Solmi M, Noale M, Vaona A, Demurtas J, et al. Dietary magnesium intake and fracture risk: data from a large prospective study. $\mathrm{Br}$ J Nutr. (2017) 117:1570-6. doi: 10.1017/S0007114517001350

270. Boyle NB, Lawton C, Dye L. The effects of magnesium supplementation on subjective anxiety and stress-a systematic review. Nutrients. (2017) 9:E429. doi: 10.3390/nu9050429.

271. Tarleton EK, Littenberg B. Magnesium intake and depression in adults. J Am Board Fam Med. (2015) 28:249-56. doi: 10.3122/jabfm.2015.02.140176

272. You HJ, Cho S-E, Kang S-G, Cho S-J, Na K-S. Decreased serum magnesium levels in depression: a systematic review and meta-analysis. Nord J Psychiatry. (2018) 1-8. doi: 10.1080/08039488.2018.1538388

273. Tarleton EK, Littenberg B, MacLean CD, Kennedy AG, Daley C. Role of magnesium supplementation in the treatment of depression: a randomized clinical trial. PLOS ONE. (2017) 12:e018(0067) doi: 10.1371/journal.pone.0180067

274. Serefko A, Szopa A, Poleszak E. Magnesium and depression. Magnes Res. (2016) 29:112-9. doi: 10.1684/mrh.2016.0407

275. Pochwat B, Nowak G, Szewczyk B. Brain glutamic acid decarboxylase$67 \mathrm{kDa}$ alterations induced by magnesium treatment in olfactory bulbectomy and chronic mild stress models in rats. Pharmacol Rep. (2016) 68:881-5. doi: 10.1016/j.pharep.2016.04.011

276. El-Sayed E, Ibrahim K. Effect of the types of dietary fats and nondietary oils on bone metabolism. Crit Rev Food Sci Nutr. (2017) 57:653-8. doi: 10.1080/10408398.2014.914889

277. Kim H-J, Ohk B, Yoon HJ, Kang WY, Seong SJ, Kim S-Y, et al. Docosahexaenoic acid signaling attenuates the proliferation and differentiation of bone marrow-derived osteoclast precursors and promotes apoptosis in mature osteoclasts. Cell Signal. (2017) 29:226-32. doi: 10.1016/j.cellsig.2016.11.007

278. Montes Chañi EM, Pacheco SOS, Martínez GA, Freitas MR, Ivona JG, Ivona JA, et al. Long-term dietary intake of chia seed is associated with increased bone mineral content and improved hepatic and intestinal morphology in sprague-dawley rats. Nutrients. (2018) 10:E922. doi: 10.3390/ nu10070922

279. Lavado-García J, Roncero-Martin R, Moran JM, Pedrera-Canal M, Aliaga I, Leal-Hernandez $\mathrm{O}$, et al. Long-chain omega-3 polyunsaturated fatty acid dietary intake is positively associated with bone mineral density in normal and osteopenic Spanish women. PloS ONE. (2018) 13:e019. doi: 10.1371/journal.pone.0190539.

280. Dong H, Hutchins-Wiese H, Kleppinger A, Annis K, Liva E, Lammi-Keefe $\mathrm{C}$, et al. Effects of Omega-3 polyunsaturated fatty acid supplementation on bone turnover in older women. Int J Vitam Nutr Res. (2014) 84:124-32. doi: 10.1024/0300-9831/a000199

281. Shen D, Zhang X, Li Z, Bai H, Chen L. Effects of omega-3 fatty acids on bone turnover markers in postmenopausal women: systematic review and meta-analysis. Climacteric J Int Menopause Soc. (2017) 20:522-7. doi: 10.1080/13697137.2017.1384952

282. Wauquier F, Léotoing L, Philippe C, Spilmont M, Coxam V, Wittrant Y. Pros and cons of fatty acids in bone biology. Prog Lipid Res. (2015) 58:121-45. doi: 10.1016/j.plipres.2015.03.001.

283. Thesing CS, Bot M, Milaneschi Y, Giltay EJ, Penninx BWJH. Omega-3 and omega-6 fatty acid levels in depressive and anxiety disorders. Psychoneuroendocrinology. (2018) 87:53-62. doi: 10.1016/j.psyneuen.2017.10.005

284. McCabe D, Lisy K, Lockwood C, Colbeck M. The impact of essential fatty acid, B vitamins, vitamin C, magnesium and zinc supplementation on stress levels in women: a systematic review. JBI Database Syst Rev Implement Rep. (2017) 15:402-53. doi: 10.11124/jbisrir-2015-2298

285. Burhani MD, Rasenick MM. Fish oil and depression: the skinny on fats. J Integr Neurosci. (2017) 16(Suppl 1):S115-24. doi: 10.3233/ JIN-170072

286. Oshima Y, Watanabe $\mathrm{T}$, Endo $\mathrm{S}$, Hata S, Watanabe $\mathrm{T}$, Osada $\mathrm{K}$, et al. Effects of eicosapentaenoic acid and docosahexaenoic acid on anxiety-like behavior in socially isolated rats. Biosci Biotechnol Biochem. (2018) 82:716-23. doi: 10.1080/09168451.2017. 1403888 
287. Tang M, Jiang P, Li H, Liu Y, Cai H, Dang R, et al. Fish oil supplementation alleviates depressant-like behaviors and modulates lipid profiles in rats exposed to chronic unpredictable mild stress. BMC Complement Altern Med. (2015) 15:239. doi: 10.1186/s12906-015-0778-1

288. Carter JR, Schwartz CE, Yang H, Joyner MJ. Fish oil and neurovascular reactivity to mental stress in humans. Am J Physiol Regul Integr Comp Physiol. (2013) 304:R523-530. doi: 10.1152/ajpregu.00031.2013

289. Bradbury J, Myers SP, Meyer B, Brooks L, Peake J, Sinclair AJ, et al. Chronic psychological stress was not ameliorated by omega-3 eicosapentaenoic acid (EPA). Front Pharmacol. (2017) 8:551 doi: 10.3389/fphar. 2017.00551
Conflict of Interest Statement: The authors declare that the research was conducted in the absence of any commercial or financial relationships that could be construed as a potential conflict of interest.

Copyright (C) 2019 Kelly, McDonald, Jensen, Sidles and LaRue. This is an open-access article distributed under the terms of the Creative Commons Attribution License (CC $B Y)$. The use, distribution or reproduction in other forums is permitted, provided the original author(s) and the copyright owner(s) are credited and that the original publication in this journal is cited, in accordance with accepted academic practice. No use, distribution or reproduction is permitted which does not comply with these terms. 